In situ formation and characterisation of singly ionised atomic europium in rare gas matrices-Luminescence spectroscopy and MP2 calculations

Owen Byrne, Barry Davis, and John G. McCaffrey

Citation: J. Chem. Phys. 142, 054307 (2015); doi: 10.1063/1.4907201

View online: http://dx.doi.org/10.1063/1.4907201

View Table of Contents: http://aip.scitation.org/toc/jcp/142/5

Published by the American Institute of Physics 


\title{
In situ formation and characterisation of singly ionised atomic europium in rare gas matrices_Luminescence spectroscopy and MP2 calculations
}

\author{
Owen Byrne, Barry Davis, and John G. McCaffrey ${ }^{\mathrm{a})}$ \\ Department of Chemistry, Maynooth University, National University of Ireland-Maynooth, County Kildare, \\ Ireland
}

(Received 19 November 2014; accepted 19 January 2015; published online 4 February 2015)

\begin{abstract}
Irradiation of atomic europium isolated in the solid rare gases, with low intensity laser excitation of the $y^{8} \mathrm{P} \leftarrow a^{8} \mathrm{~S}$ resonance transition at ca. $465 \mathrm{~nm}$, is found to produce singly charged europium cations $\left(\mathrm{Eu}^{+}\right)$in large amounts in xenon and in smaller amounts in argon. Confirmation of the formation of matrix-isolated $\mathrm{Eu}^{+}$is obtained from characteristic absorption bands in the UV and in the visible spectral regions. The luminescence produced with excitation of the cation bands is presented in greatest detail for Eu/Xe and assigned. Excitation of the $4 \mathrm{f}^{7}\left({ }^{8} \mathrm{~S}_{7 / 2}\right) 6 \mathrm{p}_{3 / 2}$ absorption bands of $\mathrm{Eu}^{+}$ between 390 and $410 \mathrm{~nm}$ produces emission which is quite distinct from that resulting from excitation of the $4 \mathrm{f}^{7}\left({ }^{8} \mathrm{~S}_{7 / 2}\right) 6 \mathrm{p}_{1 / 2}$ absorption (430 to $450 \mathrm{~nm}$ ) features. The latter consists of narrow, resolved emission bands with Stokes shifts ten times smaller than the former. The observed spectral differences are discussed in relation to the different spatial symmetries of the $p_{3 / 2}$ and $p_{1 / 2}$ orbitals in these $j-j$ coupled $(7 / 2,3 / 2)_{\mathrm{J}}$ and the $(7 / 2,1 / 2)_{\mathrm{J}}$ levels. Møller-Plesset calculations are conducted to obtain the molecular parameters of the neutral $\mathrm{Eu}-\mathrm{RG}$ and cationic $\mathrm{Eu}^{+}-\mathrm{RG}$ diatomics $(\mathrm{RG}=\mathrm{Ar}, \mathrm{Kr}, \mathrm{Xe})$. From the short bond lengths and the strong binding energies obtained for the $\mathrm{Eu}^{+}-\mathrm{RG}$ species, these values suggest the isolation of the ion in small, possibly interstitial sites especially in xenon. In contrast, but consistent with previous work [O. Byrne and J. G. McCaffrey, J. Chem. Phys. 134, 124501 (2011)], the interaction potentials calculated herein for the Eu-RG diatomics suggest that the neutral Eu atom occupies tetra-vacancy (tv) and hexa-vacancy (hv) sites in the solid rare gas hosts. Possible reasons for the facile production of $\mathrm{Eu}^{+}$in the solid rare gases are discussed. The mechanism proposed is that atomic europium is also acting as an electron acceptor, providing a temporary trap for the ionised electron in the matrices. (C) 2015 AIP Publishing LLC. [http://dx.doi.org/10.1063/1.4907201]
\end{abstract}

\section{INTRODUCTION}

In recent studies of the UV-vis absorption ${ }^{1}$ and luminescence ${ }^{2}$ spectroscopy of matrix-isolated europium $(\mathrm{Eu} / \mathrm{RG})$, multiple trapping sites were identified for the atom isolated in the solid rare gases $(\mathrm{RG}=\mathrm{Ar}, \mathrm{Kr}, \mathrm{Xe})$. Using excitation spectroscopy in the $y^{8} \mathrm{P}$ state region, two thermally stable trapping sites were found to be present in $\mathrm{Ar}$ and $\mathrm{Kr}$ matrices while only a single site remains in xenon after annealing. The higher energy "blue" sites in $\mathrm{Ar}$ and $\mathrm{Kr}$ are associated with the single site in Xe. Site-specific luminescence, ${ }^{2}$ produced with $y^{8} \mathrm{P}$ state excitation at $\sim 450 \mathrm{~nm}$, allowed identification of emission occurring in the $460,570,680$, and $800 \mathrm{~nm}$ spectral regions from the electronic $y^{8} \mathrm{P}, z^{6} \mathrm{P},\left[z^{10} \mathrm{P} / a^{8} \mathrm{D}\right]$ states and the metastable $a^{10} \mathrm{D}$, respectively.

The multiple sites identified in the $y^{8} \mathrm{P}$ state excitation spectra also provided the explanation for the complex nearUV absorption bands recorded earlier by Micklitz et $a l^{3,4}$ in Ar matrices. The core $4 \mathrm{f} \rightarrow 5 \mathrm{~d}$ transitions involved would be expected to produce quite narrow absorptions but in certain matrices, such as Ar, highly structured bands were observed. This behaviour can now be attributed to multiple site occupancy in combination with crystal field splitting. ${ }^{1}$ Narrower bands were recorded for the near-UV transitions of neutral

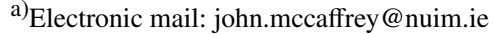

europium atoms embedded in helium droplets ${ }^{5}$ and isolated in bulk liquid helium. ${ }^{6}$ This is consistent with the much weaker interactions that arise with helium and a host environment where well defined sites of isolation do not exist. The occurrence of bubble formation in the excited states of metal atoms in liquid helium is now a well-documented phenomenon. ${ }^{7}$

In the present study, we report the production of new absorption features in rare gas matrices following low intensity laser excitation of the resonant $y^{8} \mathrm{P}$ state of atomic europium. In the case of xenon, the new features completely replace the neutral atomic bands while only partial removal of the deposited atoms is found in argon matrices. The new features exhibit distinct photophysical characteristics from the neutral atom, leading to their assignment as atomic europium cation. To the best of our knowledge, the only other reported occurrence of a metal cation formed in situ in a matrix, in the absence of an electron accepting species, is Bondybey's work ${ }^{8}$ on atomic calcium. In that case, $\mathrm{Ca} / \mathrm{Ar}$ matrices were exposed to laser radiation with energies of $10.2 \mathrm{eV}$ and $6.63 \mathrm{eV}$, which are higher than the ionisation energy (IE) of free atomic $\mathrm{Ca}(6.11$ $\mathrm{eV})$. This situation is distinct from the present system where long wavelength $(465 \mathrm{~nm}$ ) laser irradiation at $2.7 \mathrm{eV}$ is found to efficiently ionise atomic europium which has an IE of 5.67 $\mathrm{eV}$ in the gas phase.

The spectral and temporal luminescence characteristics of the species produced with photolysis are reported in detail for 
$\mathrm{Eu} / \mathrm{Xe}$ matrices and will be analysed in depth for this solid as it is the simplest host, exhibiting a single site of isolation for the neutral atom. This solid also provides the largest temperature range in annealing studies. Results obtained for the lighter rare gases $\mathrm{Kr}$ and $\mathrm{Ar}$, which exhibit multiple trapping sites, will be briefly summarised and the results for the three systems will then be discussed collectively. Ab initio potential energy curves are calculated for the neutral $\mathrm{Eu}-\mathrm{RG}$ and cationic $\mathrm{Eu}^{+}-$ RG diatomics with the objective to understand the atomic processes occurring within the rare gas matrices. Finally, possible mechanisms leading to the facile production of the ion will be presented and evaluated.

\section{METHODS}

\section{A. Experimental}

The gas handling system and vacuum apparatus used in the preparation of $\mathrm{Eu} / \mathrm{RG}$ matrix samples have been described in previous publications ${ }^{9,10}$ from our group. Europium vapour was generated by electron bombardment of Eu metal chips (Sigma Aldrich, 457965-5G, 99.9\% purity) contained in a molybdenum crucible. Samples were deposited at gas flow rates of $3 \mathrm{mmol} / \mathrm{h}$ for periods of $30 \mathrm{~min}$. The $\mathrm{Xe}, \mathrm{Kr}$, and $\mathrm{Ar}$ samples presented in this study were deposited at 26, 21, and $16 \mathrm{~K}$, respectively, followed by annealing to 60,38 , and 21 $\mathrm{K}$. This procedure of warm deposition followed by matrix annealing was followed to ensure the formation of samples with a minimum of multiple trapping sites ${ }^{2}$ of atomic Eu. A brief luminescence study was performed to check the formation of standard samples with typical Eu/RG emission and excitation features. ${ }^{2}$ Following this, samples underwent unfocussed dye laser irradiation of the $y^{8} \mathrm{P}$ state for periods of $15-30 \mathrm{~min}$ at laser energies in the range $250-300 \mu \mathrm{J} / \mathrm{mm}^{2}$. The dyes used to produce laser output at $465.5 \mathrm{~nm}(\mathrm{Xe}), 451 \mathrm{~nm}(\mathrm{Kr}), 450.1 \mathrm{~nm}$ (Ar, red site), and $438.3 \mathrm{~nm}$ (Ar, blue site) are specified below.

For spectroscopic work, photoexcitation was done with a tungsten lamp (near-UV/Vis, 300-900 nm range) or a deuterium lamp (UV, 180-400 nm range). ${ }^{11,12}$ Excitation wavelengths were selected using a $0.3 \mathrm{~m}$ monochromator (Acton Research Corporation, model SpectraPro-300i) containing a 1200 grooves/mm grating blazed at $300 \mathrm{~nm}$. Emission was collected perpendicular to the excitation beam and dispersed using a $0.5 \mathrm{~m}$ monochromator (ARC, model SP500i) fitted with three gratings. The emission intensity was monitored using a photon counting (Hamamatsu, model R928-P) photomultiplier tube (PMT) detector operated at $-20{ }^{\circ} \mathrm{C}$ in a cooled housing (Photocool, model S600) or an intensified, gated charge coupled device (iCCD) detector (Andor Technologies, model iStar DH720) held at $-15^{\circ} \mathrm{C}$ by an integrated Peltier cooling system. The detector of choice was selected by a swing mirror in the SP500i which allowed the dispersed emitted radiation either to fall directly on the iCCD camera or be diverted at right angles to the photon counting PMT.

A pulsed dye laser ${ }^{12,13}$ (Quantel TDL90) pumped by the second $(532 \mathrm{~nm})$ or third $(355 \mathrm{~nm})$ harmonics of a Nd:YAG laser (Quantel YG980E) was used as the excitation source for both time-resolved measurements and laser photolysis. The temporal profile of the Nd:YAG laser pulse is about 4 ns (fwhm) and was operated at a repetition rate of $10 \mathrm{~Hz}$. The following dyes were employed for the specified spectral ranges: Stilbene 3 [415-439 nm], Coumarin 440 [420-470 $\mathrm{nm}$ ], Coumarin 460 [444-476 nm], and Coumarin 480 [462$497 \mathrm{~nm}$ ]. Laser excitation wavelengths in the UV region were generated by frequency mixing the fundamental of the YAG $(1064 \mathrm{~nm})$ with the output of a particular dye (DCM [615-666 $\mathrm{nm}$ ], Rhodamine-6G [555-580 nm], Rhodamine-B [584-619 $\mathrm{nm}]$ ). Mixing was performed using KDP (Potassium diPhosphate) crystals [Quantel MCC1 mixing crystal and Quantel QCC2 compensator]. A Pellin-Broca prism, mounted at the exit of the dye laser, was used to separate the UV output from the dye fundamental and YAG beams. Typical laser outputs of $1-3 \mu \mathrm{J} / \mathrm{mm}^{2}$ were obtained using either the oscillator of the TDL90 dye laser on its own or with the pre-amplifier.

Emission decay curves were extracted from the nanosecond time-resolved emission spectra (TRES) recorded with the iCCD detector, by taking "kinetic slices" at specific wavelengths. Decay times were obtained by fitting trial functions, convoluted with the temporal profile of the laser excitation pulse, to the extracted decay curves. When comparing recorded matrix lifetimes to gas phase values, two effects must be accounted for. The first is a correction for the effective field ${ }^{14,15}$ of the surrounding host on the guest atom. It is made with Eq. (1)

$$
\tau_{c o r}=\tau_{o b s} n\left[s\left(n^{2}-1\right)+1\right]^{2} .
$$

The formula is a function of the index of refraction of the given rare gas host, $n$, and a "shape" parameter, $s$. Values of 1.32, 1.43 , and 1.49 were used for the refractive indices of $\mathrm{Ar}, \mathrm{Kr}$, and Xe, respectively. ${ }^{16,17}$ The $s$ parameter is a depolarisation factor related to the symmetry of the site accommodating the guest atom, for spherical cavities, $s=1 / 3$. The second effect arises from the matrix shift of the emission wavelengths. Account of the matrix shift is taken with a $\lambda^{3}$-extrapolation, based on the relationship between the Einstein A coefficient for the spontaneous emission decay rate $A_{i, j}$ and the radiative lifetime $\left(\tau_{i}\right)$ of a level $i$,

$$
A_{i, j}=\left(64 \pi^{4} / 3 h \lambda^{3}\right) \mu_{i, j}^{2}={ }^{1} / \tau_{i} .
$$

\section{B. Theoretical}

Potential energy curves for the neutral (Eu-RG) and cationic $\left(\mathrm{Eu}^{+}-\mathrm{RG}\right)$ europium-rare gas diatomics $(\mathrm{RG}=\mathrm{Ar}, \mathrm{Kr}$, and $\mathrm{Xe}$ ) were calculated with second-order Møller-Plesset (MP2) theory. This was achieved with Gaussian-03 Software ${ }^{18}$ (Revision E.01) running on a PC workstation (AMD64 quadcore $2.8 \mathrm{GHz}$ processor) with the Linux Red Hat operating system (EL, Server 5.3). Atomic europium, both the neutral and the singly charged ion $\left(\mathrm{Eu}^{+}\right)$, was described using a segmented basis set, ${ }^{19,20}$ augmented by 2 pdfg diffuse functions ${ }^{21}$ and a 28 electron core potential ${ }^{20,22}$ (ECP28MWB) in which the $1 \mathrm{~s}-3 \mathrm{~d}$ shells are included in the pseudopotential core. All shells with a principal quantum number greater than 3 are treated explicitly. In particular, the $4 \mathrm{f}$ shell is included in the valence set. This basis set gave good agreement ${ }^{23}$ with experimental results for numerous diatomic lanthanide compounds $(\mathrm{EuX}, \mathrm{X}=\mathrm{H}, \mathrm{O}$, $\mathrm{F}, \mathrm{S}$ ) and was employed with success ${ }^{20}$ for calculations of the weakly bound europium dimer, $\mathrm{Eu}_{2}$. The aug-cc-pVTZ basis 
set was used as pre-defined in Gaussian-03 for Ar and $\mathrm{Kr}$ while for $\mathrm{Xe}$, the aug-cc-pVTZ-PP basis set $^{24-27}$ and 28 electron $\mathrm{ECP}^{25-27}$ was employed.

For the neutral Eu-RG diatomics, it was found that the default SCF algorithm implemented in Gaussian-03 consistently failed to achieve convergence for the single point energy calculations. To address this difficulty, a combination of CDIIS and dynamic damping (NDAMP $=\mathrm{N}$ ) was employed in the SCF procedure, where the latter replaces EDIIS in the early iterations of the convergence process. ${ }^{28}$ With this approach, convergence of stable wavefunctions was readily achieved for the majority of the points. For any remaining points which had difficulties in converging, the quadratic $\mathrm{SCF}$ procedure $(\mathrm{SCF}=$ qc) was implemented. The asymptotic limits were obtained from energy values calculated in the 25-30 ̊ range. Basis set superposition error (BSSE) was accounted for using counterpoise $^{18}(\mathrm{CP})$ correction. The potential energy curves shown were generated by cubic spline interpolation of the single point energy values determined with the $\mathrm{CP}$ correction made at each point.

\section{RESULTS}

\section{A. Eu/Xe spectra}

The solid black traces in Fig. 1 present the absorption spectra recorded for a freshly deposited $\mathrm{Eu} / \mathrm{Xe}$ sample in the visible and UV spectral regions. The strong absorption, exhibiting pronounced threefold splitting at 461.2, 465.2, and 469.7 $\mathrm{nm}$, is as previously observed ${ }^{1}$ due to the $y^{8} \mathrm{P} \leftarrow a^{8} \mathrm{~S}$ transition of atomic europium. Much weaker atomic bands, arising from the forbidden $a^{6} \mathrm{D} \leftarrow a^{8} \mathrm{~S}$ and $y^{6} \mathrm{P} \leftarrow a^{8} \mathrm{~S}$ transitions, ${ }^{1}$ are also evident between 500 and $600 \mathrm{~nm}$. The effects of 20 min laser irradiation $\left(250 \mu \mathrm{J} / \mathrm{mm}^{2}\right)$ of the $y^{8} \mathrm{P}$ state at $465.2 \mathrm{~nm}$ (position indicated by the arrow) are presented in the absorption spec- trum shown directly above by the solid blue trace. As revealed by the comparison provided, the atomic absorption features are completely removed with this photolysis and replaced by five higher energy bands occurring as the pair of bands at 445.7 and $436.2 \mathrm{~nm}$ and the triplet at 408.3, 398, and $393.5 \mathrm{~nm}$.

The origin of the five new bands in the visible region is not immediately evident, but when scans were conducted in the UV it became clear. As shown in the left panel of Fig. 1, the Eu atom absorption features centred at 311.1, 324.3, and $336.8 \mathrm{~nm}$ are removed and replaced by higher energy absorptions at 286.1, 295.9, and $305.9 \mathrm{~nm}$. The three UV features produced with laser irradiation correspond, as indicated by the labels shown, to the $4 \mathrm{f}^{6} 5 \mathrm{~d}^{1} 6 \mathrm{~s}^{1} y^{9} \mathrm{P}_{\mathrm{J}} \leftarrow 4 \mathrm{f}^{7} 6 \mathrm{~s}^{19} \mathrm{~S}$ transitions of singly ionised atomic europium, $\mathrm{Eu}^{+}$. Evidently, the splittings between the $\mathrm{J}=3,4$, and 5 spin-orbit levels of the excited $y^{9} \mathrm{P}_{\mathrm{J}}$ state are maintained in the matrix as are their relative absorption intensities, having gas phase values ${ }^{29}$ of 50, 60, and 70, respectively. However, the locations of all three matrix absorption bands are red-shifted from the gas phase by $1700 \mathrm{~cm}^{-1}$ for the three transitions. With a secure assignment of $\mathrm{Eu}^{+}$transitions in the UV-spectral region, the five bands in the visible were re-examined and found also to arise from the atomic Eu ion. However, as shown in the top panel of Fig. 2, the shifts on the matrix absorption bands in this region are not equal. The higher energy triplet exhibits a matrix redshift of $1690 \mathrm{~cm}^{-1}$, virtually the same as the three UV-bands, but the lower energy pair has a significantly smaller red-shift $\left(1330 \mathrm{~cm}^{-1}\right)$ from the gas phase position.

The photophysical characteristics of the dominant gas phase lines of singly ionised europium $\left(\mathrm{Eu}^{+}\right)$are listed in Table I. Six levels arise from $j-j$ coupling in the $4 f^{7} 6 p^{1}$ configuration which exists in the visible spectral region. Four levels, $\mathrm{J}=2,3,4$, and 5 , arise from coupling between electrons in the $4 f(j=7 / 2)$ and $6 p(j=3 / 2)$ orbitals of the $4 f^{7}\left({ }^{8} S_{7 / 2}\right) 6 p_{3 / 2}$ configuration and two, $\mathrm{J}=3$ and 4 , from those in the $\mathrm{j}=7 / 2$

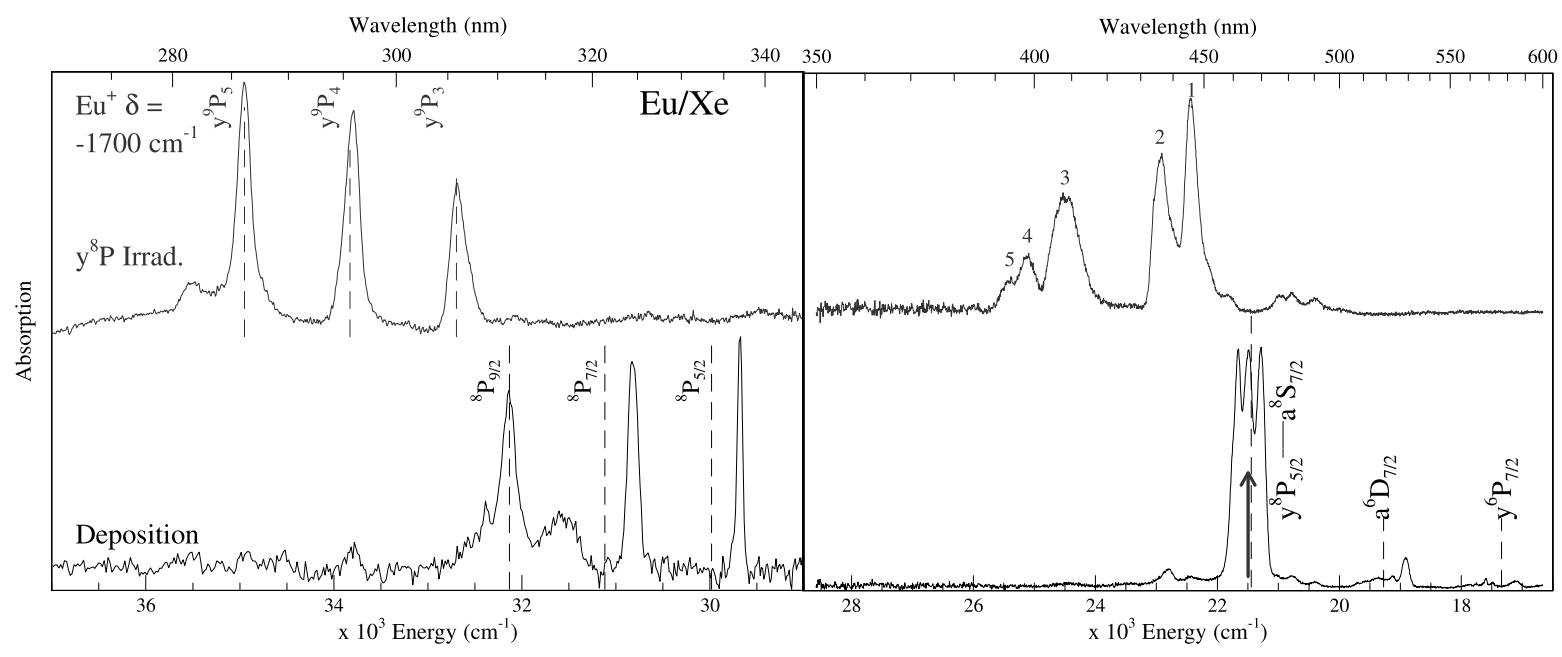

FIG. 1. Absorption spectra recorded for a Eu/Xe sample at $10 \mathrm{~K}$ in the UV (left panel) and visible spectral regions. The solid black traces were recorded following deposition at $26 \mathrm{~K}$ and sample annealing to $60 \mathrm{~K}$. Matrix absorption features pertaining to the UV $4 \mathrm{f}^{6} 5 \mathrm{~d}^{1} 6 \mathrm{~s}^{28} \mathrm{P}_{\mathrm{J}} \leftarrow 4 \mathrm{f}^{7} 6 \mathrm{~s}^{28} \mathrm{~S}$ and visible $4 \mathrm{f}^{7} 6 \mathrm{~s}^{1} 6 \mathrm{p}^{1} \mathrm{y}^{8} \mathrm{P}$ $\leftarrow 4 \mathrm{f}^{7} 6 \mathrm{~s}^{28} \mathrm{~S}$ transitions of neutral atomic europium ${ }^{1}$ are most prominent. Dashed vertical lines represent the gas phase positions of allowed transitions to the $y^{8} \mathrm{P}_{5 / 2}$ and ${ }^{8} \mathrm{P}_{\mathrm{J}}$ states of the neutral atom as well as the forbidden $a^{6} \mathrm{D} \leftarrow a^{8} \mathrm{~S}$ and $y^{6} \mathrm{P} \leftarrow a^{8} \mathrm{~S}$ transitions which are also evident. The solid blue traces present the absorption spectra recorded for the same sample following $20 \mathrm{~min}$ of $y^{8} \mathrm{P}$ state laser irradiation $\left(250 \mu \mathrm{J} / \mathrm{mm}^{2}\right)$ at $465.2 \mathrm{~nm}(\mathrm{position}$ indicated by the arrow). The atomic absorption features are completely removed being replaced by higher energy bands in both spectral regions. The dashed vertical blue lines shown in the left panel represent the gas phase positions and relative intensities of the three $y^{9} \mathrm{P} \leftarrow 4 \mathrm{f}^{7} 6 \mathrm{~s}^{2} 6 \mathrm{p}^{19} \mathrm{~S}$ transitions of the europium cation shifted to lower energy by $1700 \mathrm{~cm}^{-1}$ in the matrix. 


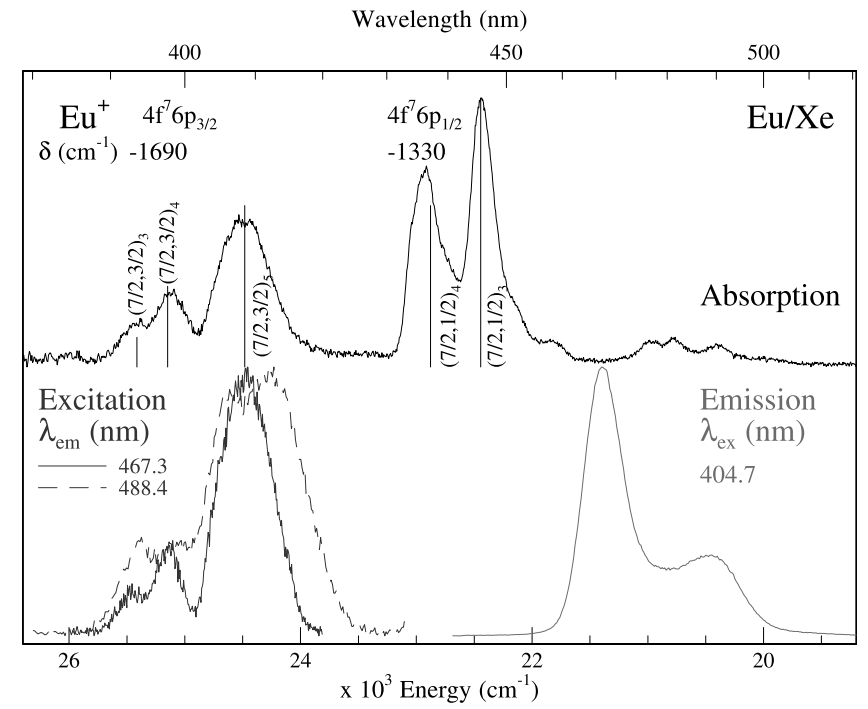

FIG. 2. The top (solid black) trace displays details of the visible absorption spectrum recorded at $10 \mathrm{~K}$ of a Eu/Xe sample following $20 \mathrm{~min}$ of $y^{8} \mathrm{P}$ state laser irradiation at $465.2 \mathrm{~nm}$. The relative intensities of the five allowed gas phase electronic transitions of $\mathrm{Eu}^{+}$from the ground state $\left[4 \mathrm{f}^{7}\left({ }^{8} \mathrm{~S}_{7 / 2}\right) 6 \mathrm{~s}{ }^{9} \mathrm{~S}_{4}\right]$ to the $\mathrm{j}$-j coupled $4 \mathrm{f}^{7}\left({ }^{8} \mathrm{~S}_{7 / 2}\right) 6 \mathrm{p}_{1 / 2}$ and $4 \mathrm{f}^{7}\left({ }^{8} \mathrm{~S}_{7 / 2}\right) 6 \mathrm{p}_{3 / 2}$ configurations are displayed as solid vertical lines. The gas phase positions have been red-shifted by the amounts specified, revealing very close agreement with the five dominant matrix bands. The red solid trace presents the emission spectrum produced with excitation of the $(7 / 2,3 / 2) \mathrm{J}$ absorption bands in the 390-410 $\mathrm{nm}$ region. Two distinct emission features are identifiable, a dominant band centred at $467.3 \mathrm{~nm}$ and a weaker one at $488.4 \mathrm{~nm}$. The excitation spectrum recorded monitoring the stronger band is displayed as a solid blue trace, while that recorded monitoring the weaker $(488.4 \mathrm{~nm})$ emission is represented by a dashed blue trace.

and $\mathrm{j}=1 / 2$ orbitals of $4 \mathrm{f}^{7}\left({ }^{8} \mathrm{~S}_{7 / 2}\right) 6 \mathrm{p}_{1 / 2}$. Because the ion has a $\mathrm{J}=4$ ground state $\left[4 \mathrm{f}^{7}\left({ }^{8} \mathrm{~S}_{7 / 2}\right) 6 \mathrm{~s}^{9} \mathrm{~S}_{4}\right]$, only five of the six levels are accessible in one-photon absorption transitions from the ${ }^{9} \mathrm{~S}_{4}$ level. The matrix absorption features are compared in the upper panel of Fig. 2 to the five gas phase transitions of $\mathrm{Eu}^{+}$. When the gas phase lines (represented by the stick spectrum) are overlaid on the matrix bands, clear agreement exists between the two in terms of the spin-orbit splittings and relative intensities. This indicates that the transitions of the free atomic ion are well maintained in the matrix environment. However, as mentioned above, the pair of ion levels derived from the two $\boldsymbol{j}$ - $\boldsymbol{j}$ coupled configurations exhibits different matrix shifts and as will now be shown in luminescence data, their emission characteristics are also quite different. This is a somewhat surprising result for what might initially be expected to be very similar excited states, which differ only by the values of the angular momenta $\mathrm{j}(=1 / 2$ or $3 / 2)$ of the $6 \mathrm{p}$ orbital. However, relativistic effects are significant in this heavy metal ion with strong spin-orbit coupling in the $6 \mathrm{p}$-orbital. This, as will be discussed ahead, results in considerable spatial differences in the $\mathrm{j}=1 / 2$ and $3 / 2$ levels of the 6 p orbital.

The two sets of new absorption features produce quite distinct emission as displayed in the lower part of Fig. 2 for the higher energy $j=3 / 2$ triplet and in Fig. 3 for the lower energy $\mathrm{j}=1 / 2$ pair. The luminescence produced with excitation of the three higher-energy (390-410 nm) absorption bands is presented in the lower part of Fig. 2. Two emission features are identifiable, a dominant band centred at $467.3 \mathrm{~nm}$ and a weaker one at $488.4 \mathrm{~nm}$. The excitation spectrum recorded monitoring the stronger band is displayed as a solid blue trace on the left in the bottom part of Fig. 2. It presents an intensity pattern that matches the absorption bands in the 390-410 nm region closely, but is narrower and better resolved. The excitation feature of greatest strength is located at $408.7 \mathrm{~nm}$, representing a large Stokes shift (SS) of $3068 \mathrm{~cm}^{-1}$ for the $467.3 \mathrm{~nm}$ emission. The excitation spectrum recorded monitoring the weaker $488.4 \mathrm{~nm}$ emission (presented by the dashed blue trace in Fig. 2) shows a maximum intensity at $412.1 \mathrm{~nm}$ yielding an even larger SS of $3791 \mathrm{~cm}^{-1}$. This excitation profile is, however, complex, exhibiting a splitting of each of the three bands into doublets.

The temporal profiles of the two emission bands were recorded at $10 \mathrm{~K}$ with pulsed dye laser excitation and timegated iCCD detection as described in the Methods section. Monitoring the more intense feature at $467 \mathrm{~nm}$ yielded the decay profile presented in the lower left of Fig. 4 in which a lifetime of $4.5 \mathrm{~ns}$ was extracted from the single exponential fit shown. The decay profile recorded monitoring the weaker emission centred at $488.4 \mathrm{~nm}$ is presented above this and yielded (491 nm was monitored to reduce spectral overlap from

TABLE I. Gas phase spectral and temporal characteristics of the allowed transitions from the $4 \mathrm{f}^{7}\left({ }^{8} \mathrm{~S}^{\circ}\right) 6 \mathrm{~s} a^{9} \mathrm{~S}_{4}$ ground state of atomic europium cation to the specified excited states. Note that some of the excited state term-symbols are indicated using the $\boldsymbol{j}$ - $\boldsymbol{j}$ coupling scheme notation ${ }^{29,42}$ which is appropriate for the $\mathbf{6} \mathbf{p}_{1 / 2}$ and the $6 \mathbf{p}_{3 / 2}$ orbitals of $\mathrm{Eu}^{+}$.

\begin{tabular}{|c|c|c|c|c|c|}
\hline \multicolumn{6}{|c|}{ Persistent lines ${ }^{29}$ of singly ionised europium $\left(\mathrm{Eu}^{+}\right)$} \\
\hline Configuration & Terms & $\lambda(\mathrm{nm})$ & $v\left(\mathrm{~cm}^{-1}\right)$ & Intensity & $\tau(\mathrm{ns})^{30}$ \\
\hline \multirow{2}{*}{$4 \mathrm{f}^{7}\left({ }^{8} \mathrm{~S}^{\circ}{ }_{7 / 2}\right) 6 \mathrm{p}_{1 / 2}$} & $(7 / 2,1 / 2)_{3}$ & 420.51 & 23774.28 & 1000 & 8.6 \\
\hline & $(7 / 2,1 / 2)_{4}$ & 412.97 & 24207.86 & 600 & 8.4 \\
\hline \multirow{3}{*}{$4 \mathrm{f}^{7}\left({ }^{8} \mathrm{~S}^{\circ}{ }_{7 / 2}\right) 6 \mathrm{p}_{3 / 2}$} & $(7 / 2,3 / 2)_{5}$ & 381.97 & 26172.83 & 600 & 6.2 \\
\hline & $(7 / 2,3 / 2)_{4}$ & 372.49 & 26838.50 & 300 & 6.9 \\
\hline & $(7 / 2,3 / 2)_{3}$ & 368.84 & 27104.07 & 110 & 7.2 \\
\hline \multirow{3}{*}{$4 f^{6}\left({ }^{7} F\right) 5 d\left({ }^{8} P\right) 6 s$} & $y^{9} \mathrm{P}_{3}$ & 290.67 & 34393.57 & 50 & 19.2 \\
\hline & $y^{9} \mathrm{P}_{4}$ & 281.39 & 35527.02 & 60 & 13.8 \\
\hline & $y^{9} \mathrm{P}_{5}$ & 272.78 & 36648.95 & 70 & 13.9 \\
\hline
\end{tabular}




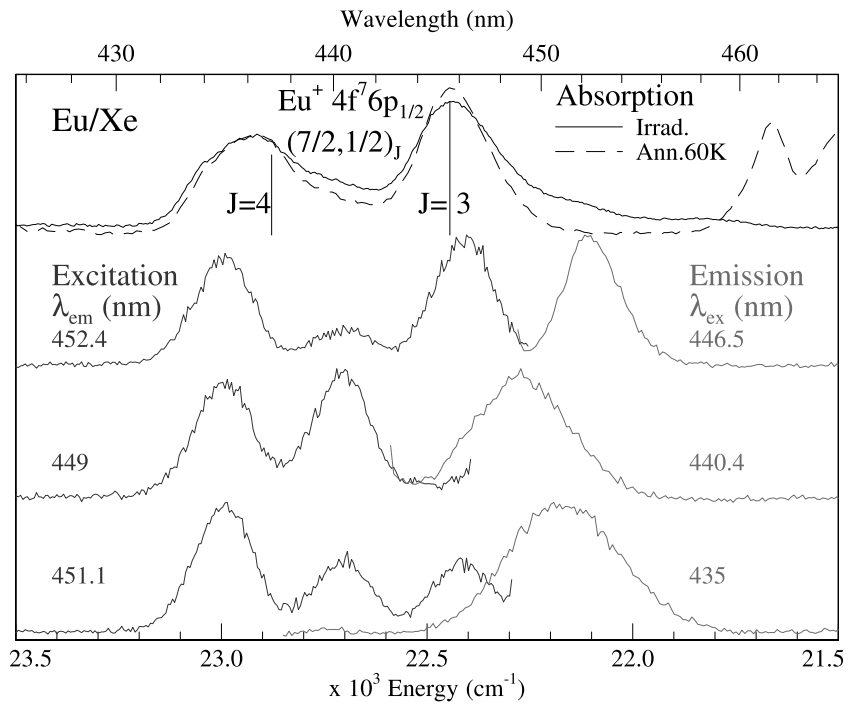

FIG. 3. The solid black trace presents an absorption spectrum in the $(7 / 2$, $1 / 2)_{\mathrm{J}}$ region of a Eu/Xe sample recorded at $10 \mathrm{~K}$ following $20 \mathrm{~min}$ of $y^{8} \mathrm{P}$ state laser irradiation at $465.2 \mathrm{~nm}$. The emission bands produced with excitation of the dominant absorption features in the $430-450 \mathrm{~nm}$ region are displayed as red solid traces. The corresponding excitation spectra are presented as solid blue traces. The dashed black trace shows the effect of annealing to $60 \mathrm{~K}$ on the absorption spectrum. Comparing with the freshly irradiated sample, it is evident that the red wing at $452 \mathrm{~nm}$ is removed and neutral Eu atom absorption features return (see feature at $461.2 \mathrm{~nm}$ ). the more intense $467 \mathrm{~nm}$ emission band) a slightly shorter lifetime of $4.0 \mathrm{~ns}$. Both values are of the same order of magnitude. Excitation of the other two absorption features in this region (398 and $393.5 \mathrm{~nm}$ ) produced the same emission features and lifetimes, indicating relaxed emission in all cases.

The emission bands produced with excitation of the dominant features in the $430-450 \mathrm{~nm}$ region are displayed in Fig. 3 and are quite distinct from that just presented in Fig. 2 for excitation in the $390-410 \mathrm{~nm}$ region. What is most immediately evident is the much smaller Stokes shift of the emission compared with what was shown in Fig. 2. Excitation at 446.5 $\mathrm{nm}$ yields emission centred at $452.4 \mathrm{~nm}$, having a narrow bandwidth of $161 \mathrm{~cm}^{-1}$ (fwhm) and a SS of $292 \mathrm{~cm}^{-1}$. In an effort to assign the origin of this feature, its temporal profile was recorded at $10 \mathrm{~K}$ and is presented in the lower right of Fig. 4. The single exponential fit shown has a lifetime of 2.1 ns. Excitation of the next highest energy absorption at 440.4 $\mathrm{nm}$ produces a broader $\left(\mathrm{fwhm}=277 \mathrm{~cm}^{-1}\right.$ ) emission feature located at $449 \mathrm{~nm}$. The temporal profile recorded monitoring this emission had a decaytime of 2.2 ns. Excitation of the final band in this spectral region at $435 \mathrm{~nm}$ generates emission centred at $451.1 \mathrm{~nm}$ exhibiting a broader width of $342 \mathrm{~cm}^{-1}$. The decay characteristics of this $451.1 \mathrm{~nm}$ emission feature were found, as presented in the upper right of Fig. 4, to have a slightly shorter lifetime of $1.8 \mathrm{~ns}$.

\section{$\mathrm{Eu}^{+} / \mathrm{Xe}$ Emission Decay Curves}
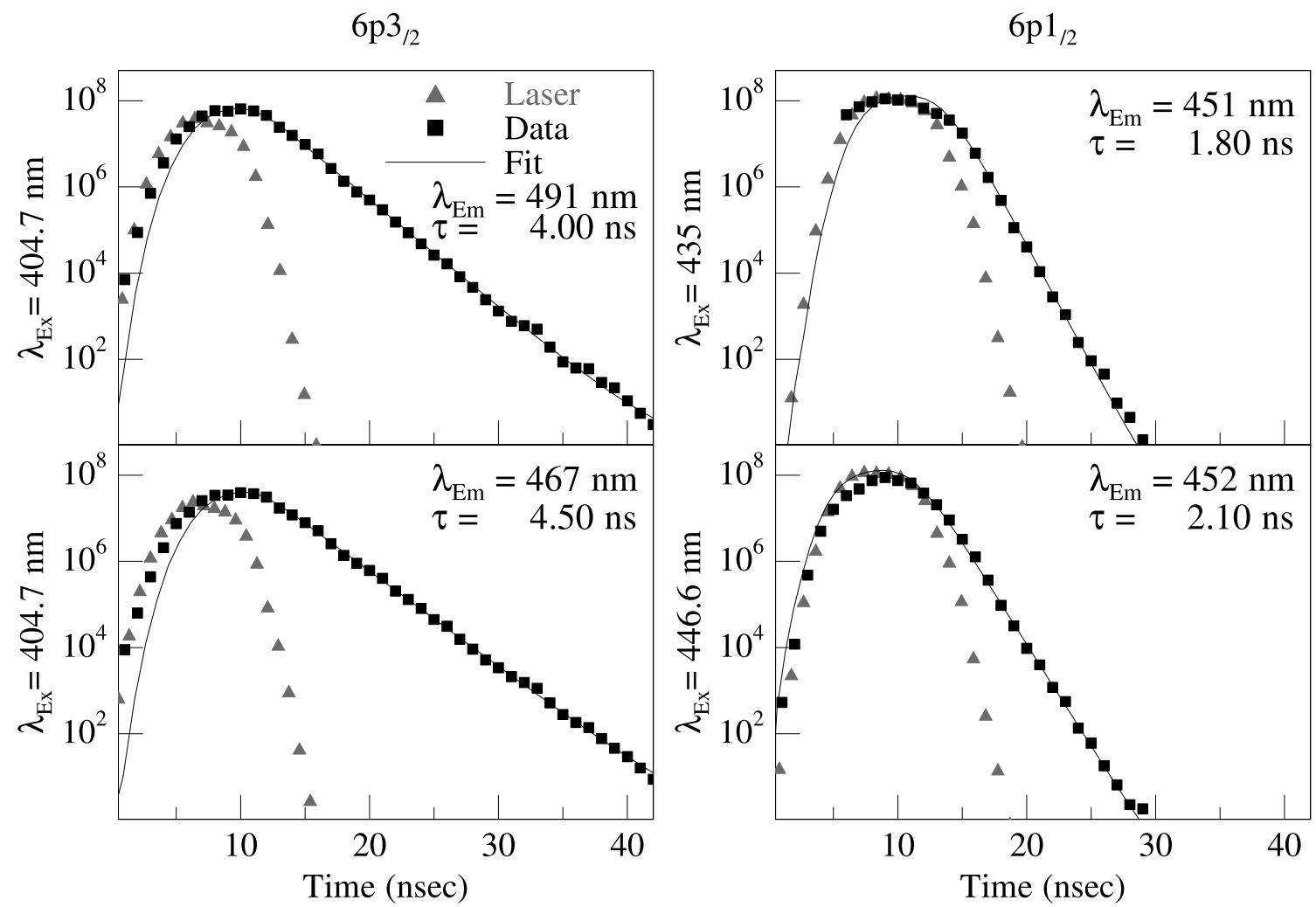

FIG. 4. Emission decay profiles of the $\mathrm{Eu}^{+} / \mathrm{Xe}$ matrix system produced with the specified excitation/emission wavelengths and recorded at $10 \mathrm{~K}$. The left panel presents the decay profiles recorded for the $6 \mathrm{p}_{3 / 2}$ emission features while the right panel presents the $6 \mathrm{p}_{1 / 2}$ features. In all cases, the emission decay profile is convoluted with the temporal profile of the laser excitation source (red triangles). The recorded decay (black squares) is fit with a single exponential. Most striking in this figure is the much shorter lifetime exhibited by the $6 \mathrm{p}_{1 / 2}$ states. 
Excitation spectra recorded monitoring these 452.4, 449, and $451.1 \mathrm{~nm}$ emission features yielded three distinct bands centred at 446.5, 440.4, and $435 \mathrm{~nm}$, respectively, as shown on the left in Fig. 3. The excitation features exhibit bandwidths of $160 \mathrm{~cm}^{-1}$ which coincide with but are narrower than the dominant 445.7 and $436.2 \mathrm{~nm}$ absorption bands. Clearly the excitation band at $440.4 \mathrm{~nm}$ is an unresolved feature in the absorption profile. When the irradiated sample was annealed to $60 \mathrm{~K}$, shown by the dashed black trace in Fig. 3, this feature and the red wing at $452 \mathrm{~nm}$ were removed. These features arise from a second minor site, identified also in the excitation spectra shown in Fig. 2. The proposal of the occurrence of a pair of sites for the ion in xenon is noteworthy as these features emerge from the neutral atom occupying a single site type. It points to more site options for the ion to reside in than its neutral parent. This may be related to the smaller size of the ion compared to the neutral as revealed in the ab initio calculations conducted, the results of which will be presented ahead.

The spectral characteristics and extracted lifetimes $\left(\tau_{10 \mathrm{~K}}\right)$ of the luminescence features of the $380-450 \mathrm{~nm}$ absorptions in solid Xe are collected in Table II where it can be seen that the two sets of levels absorbing in this region lead to a very different emission. The lifetimes measured at $10 \mathrm{~K}$ have been corrected with Eq. (1) for the effective field of the surrounding lattice $\left(\tau_{\text {cor }}\right)$. It was not possible to record emission decay curves as a function of temperature as it was found that laser irradiation at elevated temperatures caused a loss of the new absorption features. Indeed, annealing leads to the regeneration of neutral Eu atoms as revealed by the strong $y^{8} \mathrm{P}$ state absorption, evident (dashed black trace) on the extreme top right in Fig. 3. As a result, it cannot be stated that the true radiative lifetimes of the emission bands have been recorded. Notwithstanding this limitation, it is evident in Table II the corrected lifetimes are similar to the gas phase values.

\section{B. Eu/RG absorption}

The absorption spectra recorded in the near-UV/visible spectral region before and after $y^{8} \mathrm{P}$ state laser irradiation are compared in Fig. 5 for the three rare gas solids $\mathrm{Ar}, \mathrm{Kr}$, and $\mathrm{Xe}$. The corresponding spectra recorded in the UV region are presented together in Fig. 6 where it is evident that the neutral atomic absorption features are removed with varying degrees of efficiency by $y^{8} \mathrm{P}$ state irradiation. In xenon, removal is complete while in Ar it is only partial. The positions of the three new higher energy absorptions are 286.1, 295.9, and $305.9 \mathrm{~nm}$ in Xe; 283.5, 293.0, and $302.8 \mathrm{~nm}$ in $\mathrm{Kr}$; and 280.2, 289.7, and $300.1 \mathrm{~nm}$ in Ar. The intervals between the new absorption bands match the splitting of the $y^{9} \mathrm{P}$ spin-orbit levels of $\mathrm{Eu}^{+}$in the gas phase. This is illustrated in Fig. 6 where the three gas phase transitions have been red-shifted by $1380 \mathrm{~cm}^{-1}$ to obtain a match with the Kr matrix bands. This shift was found to be $1700 \mathrm{~cm}^{-1}$ in Xe (see Fig. 1) and is $1013 \mathrm{~cm}^{-1}$ in Ar.

In Fig. 5, the new absorption features in the visible spectral region for $\mathrm{Ar}$ and $\mathrm{Kr}$ are compared with $\mathrm{Xe}$. Clearly, xenon is the simplest system exhibiting the least number of bands. The higher energy $6 \mathrm{p}_{3 / 2}$ absorptions agree reasonably well in $\mathrm{Kr}$ and $\mathrm{Xe}$, while in Ar a broadening and considerable weakening of the bands occurs. Furthermore, the Ar bands are blue-shifted $\left(+1100 \mathrm{~cm}^{-1}\right)$ from the gas phase $6 \mathrm{p}_{3 / 2}$ levels while increasing

TABLE II. Spectral and temporal characteristics of the $\mathrm{Eu}^{+}$ion emission from the $4 \mathrm{f}^{7}\left({ }^{8} \mathrm{~S}^{\circ}{ }_{7 / 2}\right) 6 \mathrm{p}_{1 / 2}$ and $4 \mathrm{f}^{7}\left({ }^{8} \mathrm{~S}^{\circ}{ }_{7 / 2}\right) 6 \mathrm{p}_{3 / 2}$ states in the solid RG's at $10 \mathrm{~K}$. The emission decay times recorded in the three matrices at $10 \mathrm{~K}$ are identified by $\tau_{10 \mathrm{~K}}$ and the lifetimes corrected for the effective field of the surrounding RG solid are displayed as $\tau_{\text {Cor }}$. The bandwidths, $\Delta$, and SS are shown in $\mathrm{cm}^{-1}$. The dominant/primary $\left(1^{\circ}\right)$, secondary $\left(2^{\circ}\right)$ features are labelled according to their relative luminescence strengths. Gas phase values ${ }^{29,30}$ are shown in bold font.

\begin{tabular}{|c|c|c|c|c|c|c|}
\hline Eu/RG & $\lambda_{\mathrm{em}}(\mathrm{nm})$ & $v\left(\mathrm{~cm}^{-1}\right)$ & $\Delta\left(\mathrm{cm}^{-1}\right)$ & $\mathrm{SS}\left(\mathrm{cm}^{-1}\right)$ & $\tau_{10 \mathrm{~K}}(\mathrm{~ns})$ & $\tau_{\text {Cor }}(\mathrm{ns})$ \\
\hline$(7 / 2,1 / 2)_{3}$ & 420.51 & 23774.28 & $\ldots$ & $\ldots$ & 8.6 & $\ldots$ \\
\hline \multirow[t]{3}{*}{$\mathrm{Xe}$} & 452.4 & 22104 & 161 & 292 & 2.1 & 6.2 \\
\hline & 450.9 & 22178 & 342 & 811 & 1.8 & 5.3 \\
\hline & 448.9 & 22277 & 277 & 430 & 2.2 & 6.5 \\
\hline \multirow[t]{4}{*}{$\mathrm{Kr}$} & 453 & 22075 & 235 & 549 & 1.3 & 3.4 \\
\hline & 441.1 & 22671 & 179 & 302 & 2.4 & 6.2 \\
\hline & 436.1 & 22931 & 245 & 418 & 1.9 & 4.9 \\
\hline & 431.3 & 23186 & 176 & 399 & 2.4 & 6.2 \\
\hline \multirow[t]{4}{*}{$\mathrm{Ar}$} & 449.5 & 22247 & $399^{a}$ & 1009 & $\sim 1.1$ & 2.3 \\
\hline & 441 & 22676 & 281 & 1021 & 1.1 & 2.3 \\
\hline & 433 & 23095 & 281 & 468 & 1.8 & 3.7 \\
\hline & 426.6 & 23441 & 286 & 684 & 2.1 & 4.3 \\
\hline$(7 / 2,3 / 2)_{5}$ & 381.97 & 26172.83 & $\ldots$ & $\ldots$ & 6.2 & $\ldots$ \\
\hline $\mathrm{Xe}\left(2^{\circ}\right)$ & 488.4 & 20475 & 928 & 3909 & 4.0 & 11.8 \\
\hline$\left(1^{\circ}\right)$ & 467.3 & 21399 & 347 & 3056 & 4.5 & 13.3 \\
\hline $\operatorname{Kr}\left(1^{\circ}\right)$ & 445.2 & 22462 & 670 & 3217 & 4.6 & 11.9 \\
\hline$\left(2^{\circ}\right)$ & 424.1 & 23579 & 363 & 2064 & 3.6 & 9.3 \\
\hline $\operatorname{Ar}\left(1^{\circ}\right)$ & 418.4 & 23901 & 564 & 3321 & 4.2 & 8.6 \\
\hline$\left(2^{\circ}\right)$ & 403.9 & 24759 & 424 & 2489 & 2.0 & 4.1 \\
\hline
\end{tabular}

${ }^{\mathrm{a}}$ Linewidth estimate due to weak intensity of this feature. 


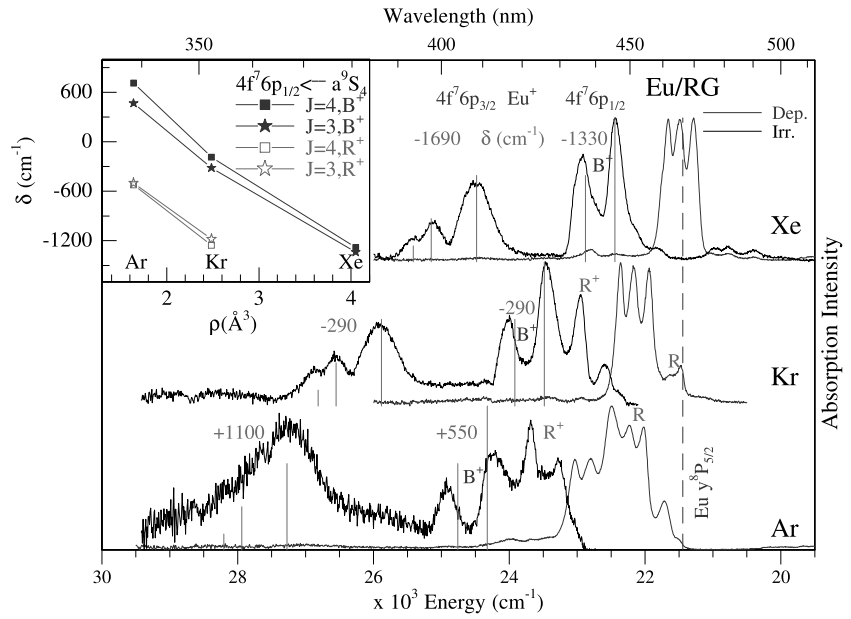

FIG. 5. The black traces present the normalised absorption spectra recorded for $\mathrm{Eu} / \mathrm{RG}$ samples following $y^{8} \mathrm{P}$ state laser irradiation of the three rare gases. Spectral positions and relative intensities of the five gas phase transitions of $\mathrm{Eu}^{+}$, shifted by the specified energies ( $\mathrm{cm}^{-1}$ units), are displayed as solid vertical red lines. The initial absorption spectra, recorded on deposition, are presented as blue solid traces for comparison. The gas phase position of the $y^{8} \mathrm{P}$ state of neutral atomic Eu is displayed as a dashed vertical line. Inset shows the gas phase to matrix frequency shifts $\left(\delta \mathrm{cm}^{-1}\right)$ observed for each of the $(7 / 2,1 / 2)_{4},(7 / 2,1 / 2)_{3} \leftrightarrow a^{9} \mathrm{~S}_{4}$ transitions of the blue $\left(\mathrm{B}^{+}\right)$and red $\left(\mathrm{R}^{+}\right)$sites of cationic europium versus the $\mathrm{RG}$ host polarisabilities. The filled squares and stars (connected by the solid line) reveal a linear correlation between the frequency shifts and rare gas polarisability observed for the two $\mathrm{Eu}^{+}(7 / 2,1 / 2)_{4},(7 / 2,1 / 2)_{3} \leftrightarrow a^{9} \mathrm{~S}_{4}$ transitions. This allows association of the single site in $\mathrm{Xe}$ and the blue $\left(\mathrm{B}^{+}\right)$sites of $\mathrm{Ar}$ and $\mathrm{Kr}$.

red-shifts are present on the bands in the $\mathrm{Kr}\left(-290 \mathrm{~cm}^{-1}\right)$ and $\mathrm{Xe}\left(-1690 \mathrm{~cm}^{-1}\right)$ systems. Two unaccounted absorption features are present in the $\mathrm{Ar}$ and $\mathrm{Kr}$ spectra in the lower energy (red) region of the $6 \mathrm{p}_{1 / 2}$ absorption. The occurrence of these additional bands (labelled $\mathrm{R}^{+}$in Fig. 5) is explained by the existence of a second site of isolation for the neutral atom, shown by the blue traces on the right. This red site (R), originally occupied by the neutral atom on deposition, thereby leads to the isolation of the europium ion in a distinct lattice position, as will be discussed later.

The comparisons shown in Figs. 5 and 6 for the three rare gas systems reveal contrasting behaviour in the two spectral regions. First, the features pertaining to two sites of isolation of the ion in $\mathrm{Ar}$ and $\mathrm{Kr}$ are not obvious for the UV transitions (Fig. 6) while they are quite pronounced in the visible region (Fig. 5). This is because the former are core ( $\rightarrow$ d type) transitions which are expected to be spectrally narrow. It is therefore proposed that underlying site structure exists on these bands but which could not be identified with the resolution available in the present study. The two spectral regions also show quite different matrix shifts. The UV bands show the simplest behaviour where red-shifts of varying extents (1700, 1380 , and $1013 \mathrm{~cm}^{-1}$ ) are observed in the three matrices (Xe, $\mathrm{Kr}$, and Ar, respectively). By contrast, the behaviour in the visible is complex. Thus, a blue-shift exists on the $6 \mathrm{p}_{1 / 2}$ and $6 \mathrm{p}_{3 / 2}$ transitions of the ion in Ar; both bands are strongly redshifted in Xe while the red-shift is much smaller in $\mathrm{Kr}$. On the basis of the strongly bound $\mathrm{Eu}^{+} / \mathrm{RG}$ ground state interactions (see calculated results presented ahead), this behaviour must mean the excited UV y ${ }^{9} \mathrm{Pj}$ levels are attractive while the $6 \mathrm{p}_{1 / 2}$ and $6 p_{3 / 2}$ states are repulsive, at least in the case of Ar.
It is evident in Fig. 5, and even more so in Fig. 6, that the efficiency of neutral to ion conversion depends strongly on the host solid. Thus, complete ion conversion occurs in xenon while it is incomplete in $\mathrm{Kr}$ and only partial in Ar. This points to the host playing a significant role in stabilising the charged species arising from the photoionisation event.

\section{Eu/RG luminescence}

Further characterisation of the $\mathrm{Eu}^{+}$ions formed in the solid rare gases is achieved with the luminescence data presented in Figs. 7 and 8 for $\mathrm{Eu} / \mathrm{Kr}$ and $\mathrm{Eu} / \mathrm{Ar}$, respectively. As was observed in the $\mathrm{Eu} / \mathrm{Xe}$ system, the emission falls into two distinct categories - narrow bands with small Stokes shifts in the $420-450 \mathrm{~nm}$ range and broader bands present in the 400 $490 \mathrm{~nm}$ range.

\section{1. $420-450 \mathrm{~nm}$ range}

The luminescence occurring in this region arises from excitation of the $4 \mathrm{f}^{7}\left({ }^{8} \mathrm{~S}_{7 / 2}^{\circ}\right) 6 \mathrm{p}_{1 / 2}$ configuration of europium ions which exhibits two electronic levels $(7 / 2,1 / 2)_{3}$ and $(7 / 2$, $1 / 2)_{4}$. Several narrow emission bands, exhibiting small Stokes shifts are observed, as is most evident for $\mathrm{Eu} / \mathrm{Kr}$ in Fig. 7. This behaviour is also observed for $\mathrm{Eu} / \mathrm{Ar}$, but not as well exhibited in Fig. 8 due to the reduced ion formation in this lighter solid. The emission decaytimes recorded for these bands are collected in Table II for the three rare gases used as host solids. The temporal and spectral characteristics of these $(7 / 2$, $1 / 2)_{3}$ and $(7 / 2,1 / 2)_{4}$ states in the gas phase are summarised in Table I. When the observed lifetimes are corrected for the effective field of the solid, the resulting nanosecond values compare favourably to the values of 8.6 and $8.4 \mathrm{~ns}$ for the $4 \mathrm{f}^{7}\left({ }^{8} \mathrm{~S}_{7 / 2}^{\circ}\right) 6 \mathrm{p}_{1 / 2} \leftrightarrow a^{9} \mathrm{~S}_{4}^{\circ}$ transitions in the gas phase. ${ }^{30}$ This agreement is a further support for the assignment of these features as emission of the $4 \mathrm{f}^{7}\left({ }^{8} \mathrm{~S}_{7 / 2}^{\circ}\right) 6 \mathrm{p}_{1 / 2}$ states of matrixisolated europium cation.

The large number of features observed in this spectral region is attributed to emission from multiple sites in Ar and $\mathrm{Kr}$ matrices and duplicated by the two spin-orbit levels. Additional features may arise from further crystal-field splitting of these levels. The emission will be analysed further ahead in relation to site occupancy. It should be pointed out that the $\mathrm{Eu} / \mathrm{Kr}$ 420/392 nm emission/excitation pair is considerably weaker than the other features shown in Fig. 7. The excitation scan of this feature matches the highest energy absorption band exactly but the emission band is narrower than the rest and is evidently weak. The reason for the extreme weakness of this emission is currently not understood.

\section{2. $400-490 \mathrm{~nm}$ range}

Absorptions in the higher energy visible region are attributed to transitions to the $(7 / 2,3 / 2)_{3},(7 / 2,3 / 2)_{4}$, and $(7 / 2,3 / 2)_{5}$ levels in the $4 \mathrm{f}^{7}\left({ }^{8} \mathrm{~S}_{7 / 2}^{\circ}\right) 6 \mathrm{p}_{3 / 2}$ configuration. The locations of the absorption transitions to these three levels of europium cations in the gas phase are provided in Fig. 9 by the dashed vertical lines. Comparison with the recorded excitation spectra in this figure reveals the pronounced red-shift in $\mathrm{Xe}$, the minor one in $\mathrm{Kr}$, and the blue-shift in Ar. Excitation into these bands 

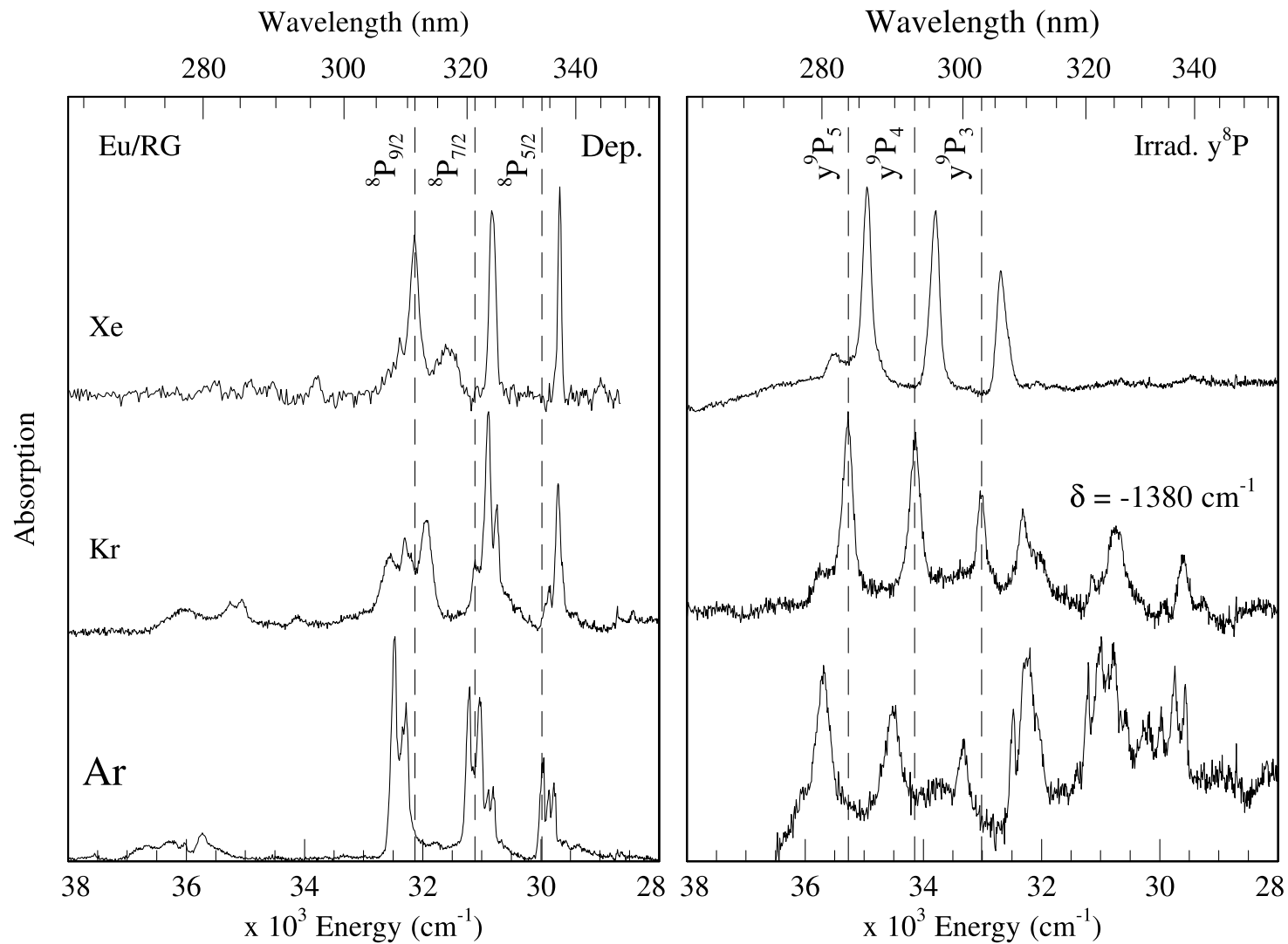

FIG. 6. UV absorption spectra of the Eu/RG samples. The left panel displays the spectra recorded in this region on deposition with the dashed vertical lines representing the gas phase positions of the ${ }^{8} \mathrm{P}$ states of atomic Eu. The right panel presents the absorption spectra in this region following $y^{8} \mathrm{P}$ state laser irradiation. The dashed vertical lines represent the gas phase positions of the $y^{9} \mathrm{P}$ states of europium cation shifted to lower energy by $1350 \mathrm{~cm}^{-1}$ to obtain a match with the $\mathrm{Kr}$ spectra. Noteworthy is the difference in the efficiency of the cation production in the three matrices. In Xe, it is complete while in Ar it is only partial. The bandwidths of the right traces are broader than the original spectra recorded due to the lower resolution employed in order to compensate for decreased sample throughput following laser irradiation.

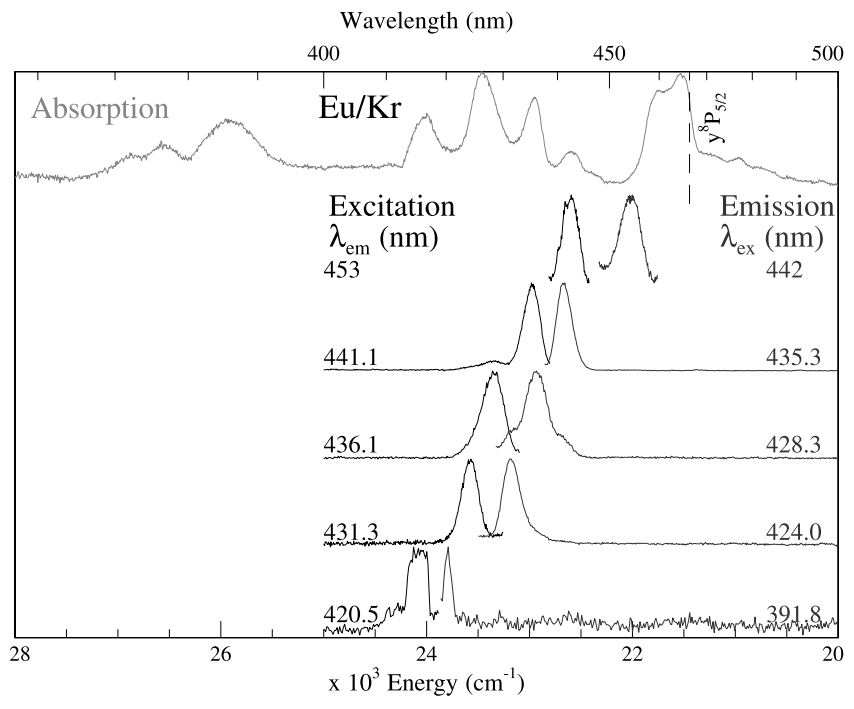

FIG. 7. A summary plot of the $\operatorname{Eu}^{+} 4 \mathrm{f}^{7}\left({ }^{8} \mathrm{~S}^{\circ} 7 / 2\right) 6 \mathrm{p}_{1 / 2}$ luminescence recorded in an irradiated $\mathrm{Eu} / \mathrm{Kr}$ sample. The spectra were recorded following $\mathrm{Kr}$ matrix deposition at $21 \mathrm{~K}$, annealing to $38 \mathrm{~K}$ followed by blue site $y^{8} \mathrm{P}$ state laser irradiation. The top trace presents the absorption spectrum in this region while the position of the gas phase $y^{8} \mathrm{P}$ transition of neutral atomic Eu is shown by the dashed vertical line. All the excitation/emission features recorded for the $\mathrm{J}=3$ and 4 levels of the $(7 / 2,1 / 2)$ configuration of $\mathrm{Eu}^{+}$are shown by the underlying traces.

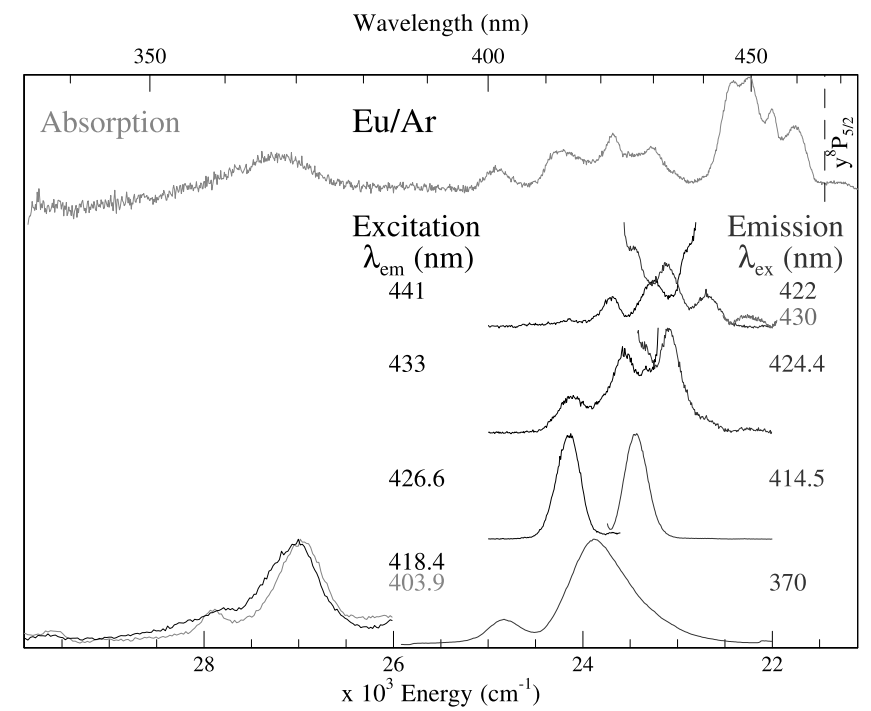

FIG. 8. Summary plot of the luminescence produced in Eu/Ar following $y^{8} \mathrm{P}$ state laser irradiation. Spectra were recorded following sample deposition at $16 \mathrm{~K}$, matrix annealing to $21 \mathrm{~K}$ followed by $y^{8} \mathrm{P}$ state laser irradiation. Top trace presents the absorption spectrum in this region, lowest trace displays the $370 \mathrm{~nm}$ luminescence, and the $395-440 \mathrm{~nm}$ spectroscopy is presented in the interlying traces. The spectral position of the gas phase $y^{8} \mathrm{P}$ transition of atomic $\mathrm{Eu}$ is shown by the dashed vertical line. 


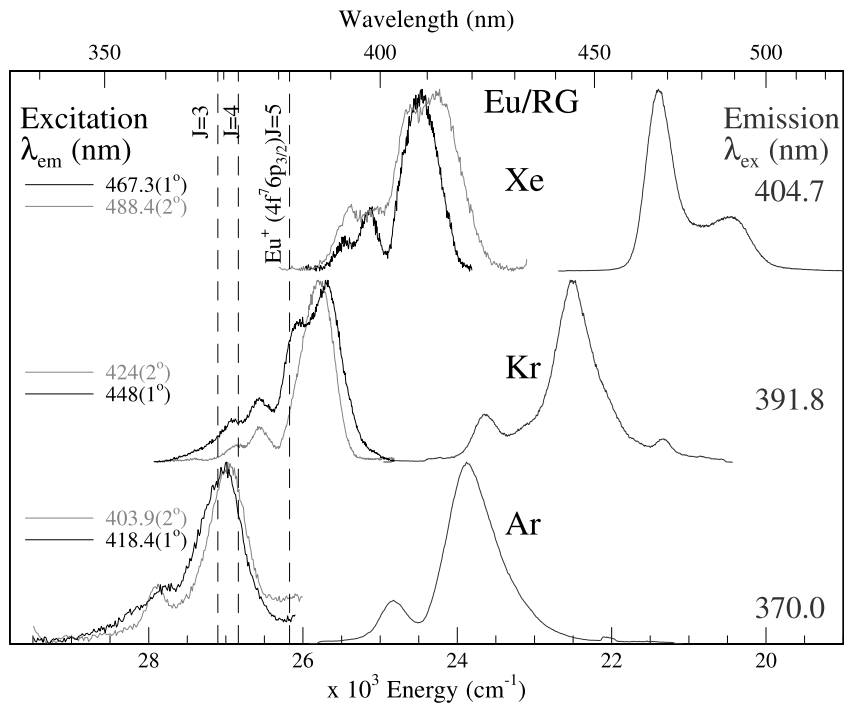

FIG. 9. A summary of the $\operatorname{Eu}^{+} 4 \mathrm{f}^{7}\left({ }^{8} \mathrm{~S}_{7 / 2}^{\circ}\right) 6 \mathrm{p}_{3 / 2}$ luminescence features recorded for the three rare gas solids. Excitation spectra are shown to the left. The solid traces were recorded monitoring more intense $\left(1^{\circ}\right)$ emission, while the dashed traces were monitoring the weaker $\left(2^{\circ}\right)$ emission. The emission spectra are displayed as solid traces to the right. The spectral positions of the three gas phase absorptions reaching the $\mathrm{J}=3,4$, and 5 levels of the $(7 / 2,3 / 2)$ configuration are shown by the dashed vertical lines for comparison with the matrix bands.

produces emission in a wider energy range as presented on the right in Fig. 9 for the three rare gas hosts. At least two distinct peaks are identifiable in the emission profile of each RG system but whose intensity relationship is different in Xe to what is observed in Ar and Kr. As shown in Fig. 9, each pair of emission bands has different excitation profiles which indicate at least two sites of isolation within the matrices. Excitation of each of the three $4 \mathrm{f}^{7}\left({ }^{8} \mathrm{~S}_{7 / 2}^{\circ}\right) 6 \mathrm{p}_{3 / 2}$ absorption features $(\mathrm{J}$ $=5,4$, and 3 ) produces the same emission profile suggesting the observed emission originates from the lowest energy $(7 / 2$, $3 / 2)_{5}$ level. Thus, only relaxed emission occurs from the $6 p_{3 / 2}$ levels.

The decaytimes recorded for the emission produced with $4 \mathrm{f}^{7}\left({ }^{8} \mathrm{~S}_{7 / 2}^{\circ}\right) 6 \mathrm{p}_{3 / 2}$ excitation in the three matrices compare, as indicated in Table II, quite well to the gas phase ${ }^{30}$ lifetime of $6.2 \mathrm{~ns}$ for the $(7 / 2,3 / 2)_{5} \leftrightarrow a^{9} \mathrm{~S}^{\circ}{ }_{4}$ transition of $\mathrm{Eu}^{+}$occurring at $381.97 \mathrm{~nm}$. When these values are corrected for the effective fields of the solid, the lifetimes are longer, in some cases up to a factor of two than the gas phase value. This effect appears to be occurring because of the large wavelength shift of the matrix emission. It is approximately $100 \mathrm{~nm}$ in the case of xenon. Thus, when the lifetimes are corrected for the effective field of the surrounding RG matrix and are plotted against a lambda cubed extrapolation (given by Eq. (2)) of the gas phase $(7 / 2,3 / 2)_{5} \leftrightarrow a^{9} \mathrm{~S}_{4}^{\circ}$ transition, the matrix corrected values lie close to the $\lambda^{3}$ curve (Fig. V.31, Ref. 31). This allows confident assignment of these features as $(7 / 2,3 / 2)_{5} \leftrightarrow a^{9} \mathrm{~S}^{\circ}{ }_{4}$ fluorescence of matrix-isolated $\mathrm{Eu}^{+}$.

\section{Eu-RG potentials}

$A b$ initio potential energy curves for the ground states of both the neutral $\mathrm{Eu}-\mathrm{RG}$ and the cationic $\mathrm{Eu}^{+}-\mathrm{RG}$ diatomics were obtained with the MP2 method and the basis sets de- scribed in Sec. II. When corrected for BSSE, well depths of 677,1079 , and $1662 \mathrm{~cm}^{-1}$ were obtained for the $\mathrm{Eu}^{+}-\mathrm{RG}$ series, $\mathrm{RG}=\mathrm{Ar}, \mathrm{Kr}$, and Xe, respectively. These potentials are shown by the blue traces in Fig. 10 and the key molecular parameters are collected in Table III. In contrast to the binding energies, which vary in magnitude by nearly $1000 \mathrm{~cm}^{-1}$, the $\mathrm{Eu}^{+}-\mathrm{RG}$ equilibrium bond lengths vary in a smaller range from 3.3 to 3.5 $\AA$ for Ar to Xe, respectively. As revealed in Table III, the bond lengths obtained by MP2 compare very favourably with the values predicted with the more sophisticated coupled-cluster single, double and triple [CCSD(T)] excitation calculations, published recently by Buchachenko and Viehland ${ }^{32}$ for the complete $\mathrm{Eu}^{+}-\mathrm{RG}$ series $\mathrm{RG}=\mathrm{He}, \mathrm{Ne}, \mathrm{Ar}, \mathrm{Kr}$, and $\mathrm{Xe}$. The binding energies predicted by MP2 are consistently underestimated but only from $4 \%$ to $7 \%$.

The MP2 calculations conducted for the neutral Eu-RG diatomics revealed very large differences in the key molecular parameters compared to their singly ionised $\mathrm{Eu}^{+}-\mathrm{RG}$ counterparts. As indicated in Table III, the binding energies of the neutrals are in the range $100-220 \mathrm{~cm}^{-1}$-nearly an order of magnitude smaller than the molecular cations and their bond lengths are larger by nearly $2 \AA$. The differences in the bond lengths, e.g., Eu-Xe $5.1 \AA$ for the neutral and $3.5 \AA$ of the cation, will have a very significant influence on the possible sites occupied by these two species in the solid rare gases. It should be pointed out that the bond lengths predicted for the neutrals are probably underestimated as is often found with the MP2 method. This remark is supported by the preliminary $\operatorname{CCSD}(\mathrm{T})$ results of Lee and Wright for the neutrals. ${ }^{33} \mathrm{In}$ contrast, the present MP2 results for the ion compare well with recent high level calculations ${ }^{32}$ as shown in Table III.

\section{DISCUSSION}

\section{A. Spectral differences in the $6 p_{1 / 2}$ and the $6 p_{3 / 2}$ levels}

As presented above, the luminescence resulting from excitation of the $4 \mathrm{f}^{7}\left({ }^{8} \mathrm{~S}_{7 / 2}^{\circ}\right) 6 \mathrm{p}_{3 / 2}$ absorption bands in the 390-410 $\mathrm{nm}$ region is quite distinct from that resulting from the $4 \mathrm{f}^{7}$ $\left({ }^{8} \mathrm{~S}_{7 / 2}^{\circ}\right) 6 \mathrm{p}_{1 / 2}$ features $(430-450 \mathrm{~nm})$. Thus, the higher energy $4 \mathrm{f}^{7}\left({ }^{8} \mathrm{~S}_{7 / 2}^{\circ}\right) 6 \mathrm{p}_{3 / 2}$ emission exhibits large $\mathrm{SS}$ and relaxes from the lowest energy state, while emission from the $4 \mathrm{f}^{7}\left({ }^{8} \mathrm{~S}_{7 / 2}^{\circ}\right)$ $6 \mathrm{p}_{1 / 2}$ configuration occurs from individual energy levels with smaller SS. A comparison of the two configurations reveals these differences originate from the $6 \mathrm{p}_{1 / 2}$ and the $6 \mathrm{p}_{3 / 2}$ orbitals involved. For most elements, differences between these orbitals, arising from spin-orbit coupling, are minimal but in the case of a heavy atomic ion, exhibiting $\mathbf{j}$-j coupling, it is pronounced with significant effects in solid state spectroscopy. The splitting between the $J=3$ levels of the $6 p_{1 / 2}$ and the $6 p_{3 / 2}$ orbitals is large-in excess of $3300 \mathrm{~cm}^{-1}$-revealing strong spin-orbit coupling in the $6 \mathrm{p}$ orbital. In essence, the contrasting spectral behaviour stems from the very different "shapes" of the $6 p_{1 / 2}$ and the $6 p_{3 / 2}$ orbitals with the former spherical while the latter is axial as expected for a conventional p-orbital. In fact, the $6 \mathrm{p}_{1 / 2}$ orbital behaves in many ways like an s-orbital, both with a shrinking of the average radii and a lowering of the energy, and is an example of a direct relativistic effect. ${ }^{34}$ Since the ground state of $\mathrm{Eu}^{+}$has an electron in the $6 \mathrm{~s}_{1 / 2}$ orbital, the 

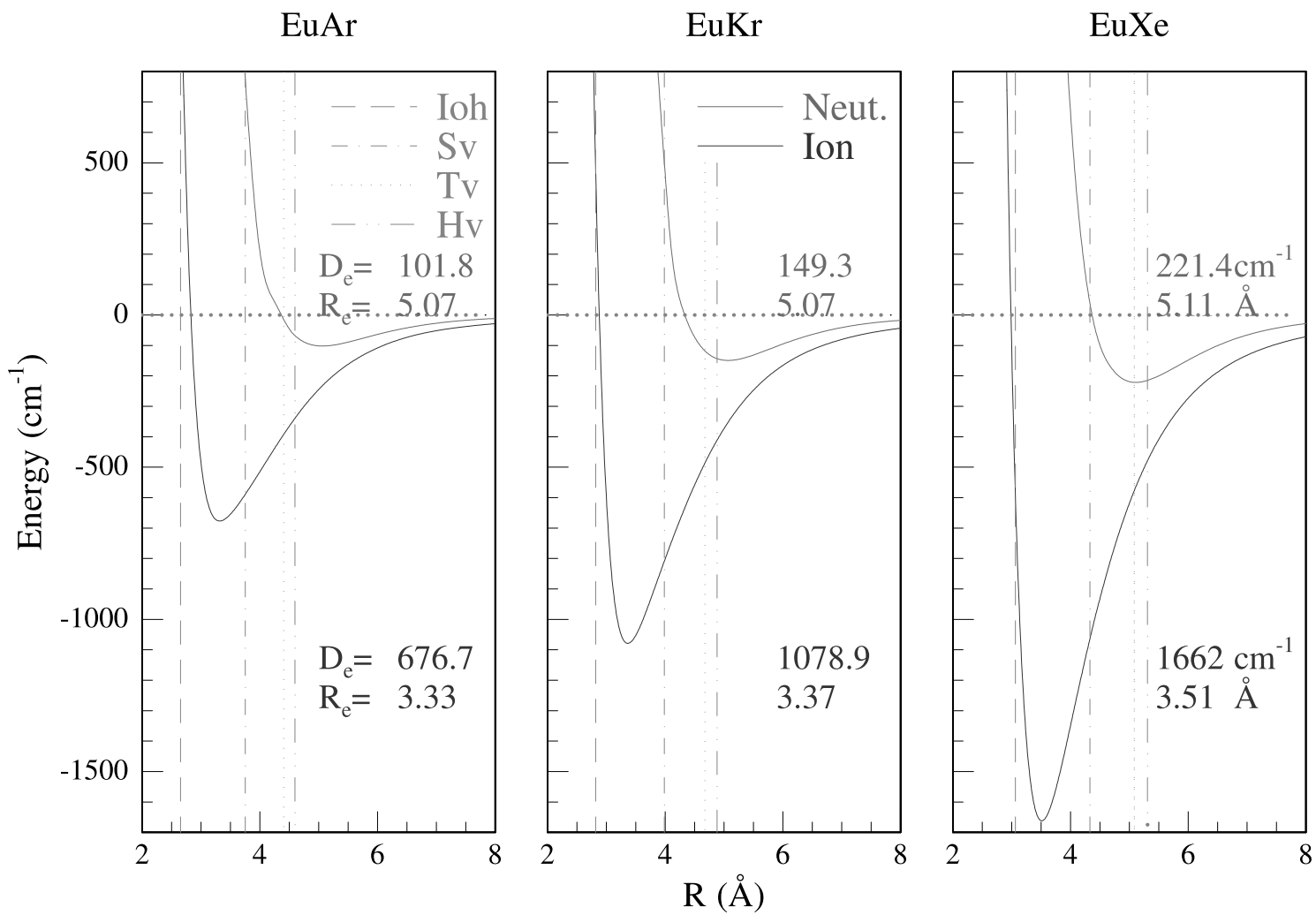

FIG. 10. Ground state interaction potentials for the $\mathrm{Eu}^{+}-\mathrm{RG}$ diatomics compared with their neutral counterparts. Both were calculated with the MP2 method and the molecular parameters extracted are collected in Table III. Also shown in this figure are the smallest spherical site sizes (values given in Table IV) present in the three solid rare gases examined in the present study. Comparison of these with the potentials gives some idea of the very different sites occupied by the neutral europium atom and the singly ionised cation.

observed transitions to the $6 \mathrm{p}_{1 / 2}$ levels, involve spatially similar orbitals. Accordingly, these two levels of this heavy atomic ion will have similar matrix-interactions. It is this (perhaps unexpected) situation, which leads to the observed small Stokes shifts and narrow bands in both excitation and emission. This behaviour is most clearly observed for $\mathrm{Eu} / \mathrm{Kr}$ in Fig. 7, where each $\mathrm{J}$ level of the $6 \mathrm{p}_{1 / 2}$ orbital in each site emits directly. Conversely, the $6 p_{3 / 2} \leftrightarrow 6 s_{1 / 2}$ transitions follow the more usual pattern (summarised in Fig. 9) for $\mathrm{p} \leftrightarrow \mathrm{s}$ transitions with relaxed emission from the lowest excited level, large Stokes shifts, and broad emission bands.

\section{B. Site occupancy}

Multiple site occupancy is identifiable on the $4 \mathrm{f}^{7}\left({ }^{8} \mathrm{~S}_{7 / 2}\right)$ $6 \mathrm{p}_{1 / 2}$ transitions in Ar and $\mathrm{Kr}$ by the occurrence of two additional absorption bands (indicated $\mathrm{R}^{+}$in Fig. 5) in the 400-
$450 \mathrm{~nm}$ region. These extra features are absent in Xe and present a situation analogous to neutral europium where Eu atoms occupy two distinct lattice vacancies (labelled $\mathrm{R}$ and $\mathrm{B}$ ) in the two lighter hosts. ${ }^{1}$ A plot of the matrix shifts of the two (J $=3,4$ ) transitions from the gas phase positions versus the host polarisability is displayed in the inset of Fig. 5. The roughly linear dependence exhibited allows the high energy doublet in $\mathrm{Kr}$ and $\mathrm{Ar}$ to be associated with the two dominant absorption features present in Xe. The red pair present in Ar and Kr has roughly the same slope indicating its association. Multiple site occupancy is not evident on the higher energy $6 p_{3 / 2}$ transitions because of the broader nature of these bands and also their weakness, especially in Ar.

As shown in Fig. 10, the calculated $\mathrm{Eu}^{+}-\mathrm{RG}$ bond lengths have values between the sizes of the matrix octahedral interstitial $\left(\mathrm{I}_{\mathrm{oh}}\right)$ site and single-vacancy ( $\mathrm{sv}$ ) sites, suggesting the guest ion may occupy very small sites in the rare gas lattices. A closer

TABLE III. Calculated molecular parameters of the ground state of the cationic $\mathrm{Eu}^{+}-\mathrm{RG}$ and neutral Eu-RG diatomics obtained with the MP2 method. The recent results obtained for the $\mathrm{Eu}^{+}-\mathrm{RG}$ species by Buchachenko and Viehland ${ }^{32}$ using CCSD(T) methods are provided in the column on the right revealing close agreement with the current MP2 results for the cations.

\begin{tabular}{|c|c|c|c|c|c|c|}
\hline \multirow[b]{2}{*}{$\mathrm{RG}$} & \multicolumn{2}{|c|}{$\operatorname{De}\left(\mathrm{cm}^{-1}\right)$} & \multicolumn{2}{|c|}{ re $(\AA)$} & \multicolumn{2}{|c|}{$\mathrm{Eu}^{+}-\mathrm{RG}^{32}$} \\
\hline & $\mathrm{Eu}^{+}-\mathrm{RG}$ & Eu-RG & $\mathrm{Eu}^{+}-\mathrm{RG}$ & Eu-RG & $\operatorname{De}\left(\mathrm{cm}^{-1}\right)$ & re $(\AA)$ \\
\hline $\mathrm{Ar}$ & 677 & 102 & 3.33 & 5.07 & 732 & 3.31 \\
\hline $\mathrm{Kr}$ & 1079 & 149 & 3.37 & 5.07 & 1167 & 3.37 \\
\hline $\mathrm{Xe}$ & 1662 & 221 & 3.51 & 5.11 & 1709 & 3.53 \\
\hline
\end{tabular}


TABLE IV. Site sizes in Angstrom units ( $\AA$ ) for specific spherically symmetric site types in the solid rare gases as determined from the lattice parameter, $a$, of each $f c c$ solid. ${ }^{43}$ The MP2 calculated bond lengths for the ground states of the neutral $\operatorname{Eu}\left(a^{8} \mathrm{~S}_{7 / 2}\right)$-RG and cationic $\operatorname{Eu}^{+}\left(a^{9} \mathrm{~S}_{4}\right)$-RG diatomics are also presented in Angstroms.

\begin{tabular}{lccccccc}
\hline \hline $\mathrm{RG}$ & $a$ & \multicolumn{1}{c}{$\mathrm{I}_{\mathrm{oh}}$} & $\mathrm{sv}$ & $\mathrm{tv}$ & $\mathrm{Hv}$ & $\mathrm{Eu}-\mathrm{RG}$ & $\mathrm{Eu}^{+}-\mathrm{RG}$ \\
\hline $\mathrm{Ar}$ & 5.31 & 2.655 & 3.755 & 4.403 & 4.598 & 5.07 & 3.32 \\
$\mathrm{Kr}$ & 5.64 & 2.82 & 3.988 & 4.676 & 4.884 & 5.07 & 3.37 \\
$\mathrm{Xe}$ & 6.13 & 3.065 & 4.330 & 5.083 & 5.308 & 5.11 & 3.51 \\
\hline \hline
\end{tabular}

examination of the site sizes (vertical dashed lines) and the cationic potential energy curves (blue traces) in Fig. 10 reveals that only $\mathrm{Eu}^{+}-\mathrm{Xe}$ has an attractive interaction at the distance of the $\mathrm{I}_{\mathrm{oh}}$ site. If, however, Buschachenko and Viehland's ${ }^{32}$ $\mathrm{CCSD}(\mathrm{T})$ potentials are used, $\mathrm{Eu}^{+}-\mathrm{Kr}$ also has a weakly attractive interaction at the distance of the $\mathrm{I}_{\mathrm{oh}}$ site. As higher energy absorptions are generally attributed to smaller vacancies, the blue site present in $\mathrm{Ar}, \mathrm{Kr}$, and $\mathrm{Xe}$ can be assigned to the smaller $\mathrm{I}_{\mathrm{oh}}$ site which occurs when the guest occupies an interstitial site surrounded by the six nearest neighbour host atoms arranged as an octahedron. The larger/lower energy red site, present only in $\mathrm{Ar}$ and $\mathrm{Kr}$, is attributed to Eu ions occupying the sv site created by replacing a single host atom in the $f c c$ lattice.

\section{Lattice re-arrangement}

Based on previous work, ${ }^{1}$ and supported now by the MP2 potentials calculated herein, neutral atomic europium initially occupies tetra-vacancy (tv) and hexa-vacancy (hv) sites in the solid rare gas hosts (see Fig. 10 for site size comparisons, while the molecular constants are collected in Table III). Transposition of the much smaller ions into an $\mathrm{I}_{\mathrm{oh}}$ site, which are inherent vacancies in the $f c c$ RG structure, may occur without disruption of the rare gas lattice. However, transformation from a hv or tv site to a sv site requires significant lattice re-arrangement. In this case, because of the small size of the ion, change of site occupancy more than likely involves $\mathrm{Eu}^{+}$migration within the host rather than movement of rare gas atoms toward a guest metal atom. On the other hand, because of the large mass of $\mathrm{Eu}$, extensive movement of this heavy guest atom cannot be assumed. Support for the lattice rearrangement proposal comes from results reported for the $\mathrm{Na} / \mathrm{RG}$ system ${ }^{35}$ where creating sv sites from larger tv or hv sites during irradiation has been observed. Molecular dynamic simulations of the excited state of atomic $\mathrm{Na}$ found ${ }^{35}$ a significant rearrangement of the rare gas atoms around the excited sodium due to strongly attractive interactions occurring when in the excited ${ }^{2} \pi$ state. The binding energies of the $\mathrm{Eu}^{+}-\mathrm{RG}$ species are larger than the $\mathrm{Na}\left({ }^{2} \mathrm{P}\right)-\mathrm{RG}$ interaction strengths, suggesting the Eu species may migrate to $I_{o h}$ or sv vacancies during the irradiation process in a similar manner "pulling" RG atoms into position after it has migrated.

\section{Ion formation}

As mentioned in the Introduction, calcium cations were generated in argon matrices when $\mathrm{Ca} / \mathrm{Ar}$ samples were exposed to high energy laser radiation. With energies of $10.2 \mathrm{eV}$ and $6.63 \mathrm{eV}$, both of which are in excess of the ionisation energy of free atomic $\mathrm{Ca}(6.11 \mathrm{eV})$, spectral signatures of the ion were obtained. ${ }^{8}$ However, it is also known ${ }^{36}$ that matrix hosts are able to reduce the IEs of alkali atoms by $1 \mathrm{eV}$ in $\mathrm{Ar}$ and up to $1.9 \mathrm{eV}$ in Xe. Even in the most extreme case of Xe, such a reduction would lower the IE of Eu from $5.67 \mathrm{eV}$ to $3.77 \mathrm{eV}$. This is still not low enough for Eu atoms to be ionised directly by 1 -photon absorption at the laser wavelengths employed $(<2.7 \mathrm{eV})$. The possibility of two-photon absorption events is deemed very unlikely at the low laser powers used in the present study. Indeed, lamp irradiation that occurred during prolonged spectral scans was found also to produce ions but in much smaller quantities. With excited state lifetimes of the pumped resonant states of the neutral atom measured as a few nanoseconds in our earlier work, ${ }^{2}$ sequential photon absorption is extremely improbable with cw lamp excitation. As a result of the observation of lamp-induced ion formation, albeit with greatly reduced efficiency, multi-photon sequential absorption is also not considered a significant ionisation mechanism.

Previous results reported by $\mathrm{Kasai}^{37}$ using electron spin resonance (ESR) spectroscopy found that neutral atoms of several metal elements, including $\mathrm{Eu}$, were readily ionised in rare gas matrices in the presence of an electron accepting species. With a $1 \%$ concentration of $\mathrm{HI}$ in a Eu/Ar matrix, Eu was converted to the singly ionised form using visible light from a high pressure mercury lamp. In the case of $\mathrm{Na} / \mathrm{Ar}$, it was proposed that if there is a $1 \%$ concentration of the electron-acceptor in the matrix and the chosen acceptor possesses an electron affinity (EA) of $\sim 1 \mathrm{eV}$ or larger, it is possible to "ionise" $\mathrm{Na}$ atoms $(\mathrm{IE}=5.18 \mathrm{eV})$ with yellow light $(2.5$ $\mathrm{eV})$. These considerations and the use of a low intensity laser strongly suggest that an electron accepting species is involved in the Eu system.

Our initial thought was the presence of an impurity with a large electron affinity in the matrix samples. However, this proposal can be discounted because of the use of high purity $(>99.995 \%)$ gases for the three hosts and the high-vacuum $\left(10^{-8}\right.$ millibars) conditions that are maintained in both the sample chamber and in the gas handling system. An indication of the cleanliness of the system can be obtained from the fact that samples of matrix-isolated atomic barium that were prepared in the same apparatus immediately after the Eu work did not show any evidence of barium ion formation. Atomic barium has an IE of $5.21 \mathrm{eV}$-very similar to europium and $\mathrm{Ba}^{+}$exhibits a prominent absorption at $455.4 \mathrm{~nm}$ which would be easily detectable with our set-up.

An "intrinsic" impurity which cannot be completely ignored is the possible existence of europium oxides in our samples as it is now known that the early lanthanide oxides have large $(\sim 1 \mathrm{eV})$ electron affinities. ${ }^{38}$ If present in appreciable quantities, the oxide could play a role as an electron scavenger. Once again because of the high vacuum maintained in this series of experiments, we do not consider any oxide $\left(\mathrm{Eu}-\mathrm{O}_{\mathrm{x}}\right)$ was produced from the in situ reaction of atomic europium with molecular oxygen. Moreover, due to the high melting point of europium oxide $\left(\mathrm{Eu}_{2} \mathrm{O}_{3}, \mathrm{~T}=2350^{\circ} \mathrm{C}\right)$ compared with europium metal $\left(\mathrm{T}=826^{\circ} \mathrm{C}\right)$ and the gentle vaporisation conditions employed in these depositions, we do not think significant 
amounts of the oxide were deposited. In the absence of optical absorption of europium oxide in our samples, the role played by this species in the present system is thereby not considered significant.

A clue to the possible identity of the species acting as the electron acceptor comes from the recent study of Davis and Thompson ${ }^{39}$ who measured the EA of ground state atomic europium $\left[\mathrm{Eu}\left({ }^{8} \mathrm{~S}_{7 / 2}\right)\right]$ finding a value of $1.05 \mathrm{eV}$ in the gas phase. O'Malley and Beck predict ${ }^{40}$ the negative europium ion supports a long-lived, bound excited state with a calculated lifetime of $0.23 \mathrm{~s}$. With a large EA and the predictions made in Kasai's studies, we propose that Eu is acting both as an electron acceptor and electron donor, forming $\mathrm{Eu}^{-}$and $\mathrm{Eu}^{+}$ions in the matrix. The formation of $\mathrm{Eu}^{-}$is predicted to occur by capture of an electron in the 6 porbital $^{39}$ but identification of the anion with absorption spectroscopy, was not achieved in the present UV-Vis study.

Kasai ${ }^{37}$ proposed that the host atoms located between the donor and the acceptor pair, play two very important roles in the electron transfer process. First, they impose a barrier to spontaneous transfer, thereby creating the need for photoexcitation. Second, by forming a trap about the cation and anion created (through a polarization interaction), a potential barrier prevents spontaneous return of the electron. The latter point is evidenced in our case by the fact the neutral atom can be regenerated by annealing (see Fig. 3 for Eu/Xe results). Furthermore, the stabilising effects of the host solids are revealed by the observation that much less $\mathrm{Eu}^{+}$is formed in the least polarisable host Ar, compared with Xe. In the case of Ar, the inability of this host to effectively stabilise the cation/anion pair is evidenced by the growth of europium dimer $\left(\mathrm{Eu}_{2}\right)$ during the photoexcitation process. This effect was easy to identify in the $\mathrm{Eu} / \mathrm{RG}$ systems as europium does not form metallic clusters easily on deposition in the solid rare gases. ${ }^{31}$

We acknowledge that in our matrix-isolated samples, the concentration of the Eu atoms, capable of being electron acceptors, is much lower than the 1\% HI used in Kasai's study. This is consistent with the observation that lamp irradiation does not achieve formation of Eu cations in large amounts. Ionisation only occurs fully with laser photolysis suggesting a large concentration of excited states is required. We propose that, as in the case of excited states of atomic $\mathrm{Na},{ }^{35}$ some movement of the excited Eu occurs during irradiation. Laser photolysis instantaneously forms a large number of excited states thus increasing the probability that two neighbouring Eu centres will move within the 7-8 $\mathrm{A}$ separation distance required for "spontaneous" electron transfer. Although challenging, due to the difficulty in obtaining accurate excited state interaction potentials for the Eu-RG systems, this proposal could be investigated with molecular dynamic simulations of the excited state of matrix-isolated atomic Eu.

To the best of our knowledge, the only purely metallic anion studied by the matrix isolation trapping technique with any type of spectroscopic method are the diatomic aluminium and gallium anion radicals $\mathrm{Al}_{2}^{-}$and $\mathrm{Ga}_{2}{ }^{-}$which have been studied by ESR spectroscopy. In this study, the anions were isolated in neon matrices near $4 \mathrm{~K} .{ }^{41}$ Our results reveal a unique case where the guest atom can possibly act both as electron acceptor and donor. Based on these observations, we expect other metal atoms with large electron affinities and strong $\mathrm{s}$ $\rightarrow 6 \mathrm{p}$ transitions such as $\mathrm{Tm}$ and $\mathrm{Ce}$ systems $^{39}$ will exhibit similar facile ionisation as $\mathrm{Eu}$ in the solid rare gases. The $\mathrm{Eu}^{+} / \mathrm{RG}$ system also offers the opportunity to study relativistic effects in heavy metal ions and strong spin-orbit coupling between p-orbitals of different spatial symmetries in one system.

\section{CONCLUSIONS}

Higher energy absorption bands that were produced with $y^{8} \mathrm{P}$ state laser irradiation of neutral atomic europium are identified in $\mathrm{Eu} / \mathrm{RG}$ samples. Based on their intensity distribution, spectral location, and temporal characteristics, they are attributed to the formation of $\mathrm{Eu}^{+}$cations trapped in the three rare gas matrices studied. The two electronic configurations of $\mathrm{Eu}^{+}$ present in the visible region behave very differently. The higher energy $4 \mathrm{f}^{7}\left({ }^{8} \mathrm{~S}_{7 / 2}^{\circ}\right) 6 \mathrm{p}_{3 / 2}$ configuration produces emission with large SS originating from relaxation to the lowest energy excited state. Emission from the $4 \mathrm{f}^{7}\left({ }^{8} \mathrm{~S}_{7 / 2}^{\circ}\right) 6 \mathrm{p}_{1 / 2}$ configuration occurs from individual energy levels with smaller SS. These pronounced spectral characteristics are attributed to differences in the spatial natures of the $6 \mathrm{p}_{1 / 2}$ and the $6 \mathrm{p}_{3 / 2}$ orbitalsthe former spherical, like the ground $6 \mathrm{~s}_{1 / 2}$ state, the latter axial as typically found for $\mathrm{p}$-atomic orbitals.

Multiple absorption features provided evidence of two sites of isolation of the $\mathrm{Eu}^{+}$ion. A lower energy red $\left(\mathrm{R}^{+}\right)$site is observed in $\mathrm{Ar}$ and $\mathrm{Kr}$ and a higher energy blue $\left(\mathrm{B}^{+}\right)$site is identified in all three hosts. A polarisability plot allowed identification of the $\mathrm{B}^{+}$features as corresponding to the ion trapped in the same lattice environment in each RG. The results of the interaction potentials calculated for the Eu-RG pairs suggest the blue feature corresponds to an $\mathrm{I}_{o h}$ Site. On this basis, the $\mathrm{R}^{+}$features present in $\mathrm{Ar}$ and $\mathrm{Kr}$ are then attributed to occupancy in single-vacancy sites.

The formation of $\mathrm{Eu}^{+}$ions within the $\mathrm{RG}$ lattice with relative ease is suggested to occur due to Eu atoms also acting as the electron acceptor. Verification of this proposed ionization mechanism could be probed with ESR spectroscopy as both the cation and the anion of atomic europium are paramagnetic. Although challenging, due to the difficulty in obtaining accurate excited state interaction potentials for the Eu system, molecular dynamic simulations of the transposition from the long neutral Eu-RG $(\sim 5.1 \AA)$ to the short cationic $\mathrm{Eu}^{+}-\mathrm{RG}$ $(\sim 3.3 \AA)$ species and the effect this has on the surrounding host lattice would be very interesting to do.

\section{ACKNOWLEDGMENTS}

This research was partly funded by the Embark Initiative Irish Research Council for Science and Engineering (IRCSET) and the Science Foundation Ireland (SFI), Investigator Grant No. 02/IN.1/B032. O.B. and B.D. gratefully acknowledge receipt of Ph.D. studentships from John and Pat Hume awards at N.U.I.-Maynooth. Chris Henchy's help with the use of the Gaussian programme was very beneficial. Fruitful discussions with Professor J. Mark Parnis, Trent University and Professor Mike Heaven, Emory University are gratefully acknowledged. 
${ }^{1}$ O. Byrne and J. G. McCaffrey, J. Chem. Phys. 134, 124501 (2011).

${ }^{2}$ O. Byrne and J. G. McCaffrey, J. Chem. Phys. 135, 024507 (2011).

${ }^{3}$ M. Jakob, H. Micklitz, and K. Luchner, Phys. Lett. A 57, 67 (1976).

${ }^{4}$ M. Jakob, H. Micklitz, and K. Luchner, Phys. Lett. A 61, 265 (1977).

${ }^{5}$ F. Federmann, A. Bartelt, J. D. Close, K. Hoffmann, N. Quaas, and J. P. Toennies, Z. Phys. D: At., Mol. Clusters 39, 1 (1997).

${ }^{6}$ Q. Hui and M. Takami, J. Low Temp. Phys. 119, 393 (2000).

${ }^{7}$ P. Moroshkin, V. Lebedev, and A. Weis, J. Chem. Phys. 140, 214314 (2014)

${ }^{8}$ V. E. Bondybey and J. H. English, J. Chem. Phys. 75, 492 (1981).

${ }^{9}$ M. A. Collier and J. G. McCaffrey, J. Chem. Phys. 119, 11878 (2003).

${ }^{10}$ M. A. Collier and J. G. McCaffrey, J. Chem. Phys. 122, 184507 (2005).

${ }^{11}$ M. A. Collier and J. G. McCaffrey, J. Chem. Phys. 122, 054503 (2005).

${ }^{12}$ M. A. Collier, M. C. Ryan, and J. G. McCaffrey, J. Chem. Phys. 123, 044508 (2005).

${ }^{13}$ M. A. Collier, O. Byrne, C. Murray, and J. G. McCaffrey, J. Chem. Phys. 132, 164512 (2010).

${ }^{14}$ R. L. Fulton, J. Chem. Phys. 61, 4141 (1974).

${ }^{15}$ T. Shibuya, J. Chem. Phys. 78, 5175 (1983).

${ }^{16}$ H. J. Jodl, "Solid state aspects of matrices," in Chemistry and Physics of Matrix-Isolated Species (North-Holland, 1989), The refractive index of Xe is 1.49 recorded at $60 \mathrm{~K}$ and $\lambda=488 \mathrm{~nm}$.

${ }^{17} \mathrm{P}$. Gurtler, "The index of refraction used for solid Ar at $233 \mathrm{~nm}$ is $1.32 \mathrm{~K}$ at $6 \mathrm{~K}$, that of $\mathrm{Kr}$ is 1.428 at $241 \mathrm{~nm}$ at $12 \mathrm{~K}$ " (unpublished results)

${ }^{18}$ M. J. Frisch, G. W. Trucks, H. B. Schlegel, G. E. Scuseria, M. A. Robb, J. R. Cheeseman, J. A. Montgomery, T. Vreven, K. N. Kudin, J. C. Burant, J. M. Millam, S. S. Iyengar, J. Tomasi, V. Barone, B. Mennucci, M. Cossi, G. Scalmani, N. Rega, G. A. Petersson, H. Nakatsuji, M. Hada, M. Ehara, K. Toyota, R. Fukuda, J. Hasegawa, M. Ishida, T. Nakajima, Y. Honda, O. Kitao, H. Nakai, M. Klene, X. Li, J. E. Knox, H. P. Hratchian, J. B. Cross, V. Bakken, C. Adamo, J. Jaramillo, R. Gomperts, R. E. Stratmann, O. Yazyev, A. J. Austin, R. Cammi, C. Pomelli, J. W. Ochterski, P. Y. Ayala, K. Morokuma, G. A. Voth, P. Salvador, J. J. Dannenberg, V. G. Zakrzewski, S. Dapprich, A. D. Daniels, M. C. Strain, O. Farkas, D. K. Malick, A. D. Rabuck, K. Raghavachari, J. B. Foresman, J. V. Ortiz, Q. Cui, A. G. Baboul, S. Clifford, J. Cioslowski, B. B. Stefanov, G. Liu, A. Liashenko, P. Piskorz, I. Komaromi, R. L. Martin, D. J. Fox, T. Keith, A. Laham, C. Y. Peng, A. Nanayakkara, M. Challacombe, P. M. W. Gill, B. Johnson, W. Chen, M. W. Wong, C. Gonzalez, and J. A. Pople, GAUSSIAN 03, Revision E.01 (Gaussian, Inc., Wallingford, CT, 2004).

${ }^{19}$ X. Cao and M. Dolg, J. Mol. Struct.: THEOCHEM 581, 139 (2002).

${ }^{20}$ X. Y. Cao and M. Dolg, Theor. Chem. Acc. 108, 143 (2002).

${ }^{21}$ A. Buchachenko, G. Chałasiński, and M. Szcześniak, Struct. Chem. 18, 769 (2007).
${ }^{22}$ M. Dolg, H. Stoll, and H. Preuss, J. Chem. Phys. 90, 1730 (1989).

${ }^{23}$ C. Xiaoyan, L. Wenjian, and M. Dolg, Sci. China, Ser. B: Chem. 45, 91 (2002).

${ }^{24}$ K. A. Peterson, D. Figgen, E. Goll, H. Stoll, and M. Dolg, J. Chem. Phys. 119, 11113 (2003)

${ }^{25}$ D. Feller, J. Comput. Chem. 17, 1571 (1996).

${ }^{26}$ K. L. Schuchardt, B. T. Didier, T. Elsethagen, L. Sun, V. Gurumoorthi, J. Chase, J. Li, and T. L. Windus, J. Chem. Inf. Model. 47, 1045 (2007).

${ }^{27}$ EMSL Basis Set Exchange v1.2.2, available: https://bse.pnl.gov/bse/portal.

${ }^{28}$ K. N. Kudin, G. E. Scuseria, and E. Cancès, J. Chem. Phys. 116, 8255 (2002).

${ }^{29}$ NIST Atomic Spectra Database (version 3.1.5), National Institute of Standards and Technology, Gaithersburg, MD, September 2014, last accessed January 2015, available: http://physics.nist.gov/asd3.

${ }^{30}$ E. A. Den Hartog, M. E. Wickliffe, and J. E. Lawler, Astrophys. J., Suppl. Ser. 141, 255 (2002).

${ }^{31}$ O. Byrne, Ph.D. dissertation, National University of Ireland Maynooth, 2010, http://eprints.nuim.ie/2439/.

${ }^{32}$ A. A. Buchachenko and L. A. Viehland, J. Chem. Phys. 140, 114309 (2014).

${ }^{33}$ T. Wright and E. P. F. Lee, private communication (2011).

${ }^{34} \mathrm{P}$. Schwerdtfeger and M. Seth, "Relativistic effects of the super-heavy elements," in Encyclopedia of Computational Chemistry (Wiley, New York, 1988), Vol. 4, pp. 2480-2499.

${ }^{35}$ M. Ryan, M. Collier, P. de Pujo, C. Crepin, and J. G. McCaffrey, J. Phys. Chem. A 114, 3011 (2009).

${ }^{36}$ N. Schwentner and M. Chergui, J. Chem. Phys. 85, 3458 (1986).

${ }^{37}$ P. H. Kasai, Acc. Chem. Res. 4, 329 (1971).

${ }^{38}$ C. Chi, H. Xie, R. Cong, Z. Tang, and M. Zhou, Chin. J. Chem. Phys. 24, 604 (2011).

${ }^{39}$ V. T. Davis and J. S. Thompson, J. Phys. B: At., Mol. Opt. Phys. 37, 1961 (2004).

${ }^{40}$ S. M. O’Malley and D. R. Beck, J. Phys. B: At., Mol. Opt. Phys. 38, 2645 (2005).

${ }^{41}$ A. C. Stowe, J. G. Kaup, L. B. Knight, J. R. Davis, and A. J. McKinley, J. Chem. Phys. 115, 4632 (2001).

${ }^{42}$ W. C. Martin and W. L. Wiese, Atomic Spectroscopy A Compendium of Basic Ideas Notation Data and Formulas (National Institute of Standards and Technology, Gaithersburg, MD, 1999, last accessed January 2015), available: http://physics.nist.gov/Pubs/AtSpec/node09.html.

${ }^{43}$ H. E. Hallam, Vibrational Spectroscopy of Trapped Species (Wiley - Interscience, New York, 1973). 